\title{
Searching for the natural rate of interest: a euro area perspective ${ }^{1}$
}

\author{
Jesus Crespo-Cuaresma, University of Vienna; \\ Ernest Gnan and Doris Ritzberger-Gruenwald, Austrian National Bank
}

\section{Introduction}

Estimates of the "natural rate of interest" or "equilibrium rate of interest" are a prerequisite for calculating many popular monetary policy rules and monetary stance indicators. Feedback rules such as Taylor's (1993) use the natural rate as the intercept term. Another recently much discussed indicator of the stance of monetary policy, the "real interest rate gap" (see, for example, Neiss and Nelson (2001)), is defined as the deviation of the actual short-term rate from the natural rate of interest. Obviously, to the extent that such rules were to be considered by monetary authorities, a "correct" estimate of the natural rate is central to successful macroeconomic stabilisation. This paper offers alternative estimates for the euro area, based on time series analysis, with a special focus on the complications and potential pitfalls due to the regime change and resulting break in data triggered by the inception of economic and monetary union (EMU).

The concept of the natural rate of interest goes back to Wicksell (1936), who stated that "there is a certain rate of interest on loans which is neutral in respect to commodity prices, and tends neither to raise nor to lower them". Following Laubach and Williams (2001), the natural rate of interest may be defined as the real interest rate consistent with output equalling potential and stable inflation. As the growth of potential output varies, the natural rate of interest also varies.

Woodford (2002) in his "Neo-Wicksellian framework for the analysis of monetary policy" argues that "inflation and output determination can be usefully explained ... as depending on the relation between a 'natural rate of interest' determined primarily by real factors and the central bank's rule for adjusting the short-term nominal interest rate that serves as the operating target". The natural or equilibrium real rate of interest is defined as the real rate of interest that would prevail in equilibrium under fully flexible prices. It is only in an environment with sticky prices that the distinction between the natural and actual rate of interest becomes meaningful. Sticky prices imply that after a shock the actual real interest rate takes time to adjust to the new equilibrium level. The role of monetary policy in such a world with sticky prices is to speed up adjustment of the economy to shocks by accelerating the adjustment of the actual real interest rate to a changed natural rate. In other words, monetary policy seeks to replicate the flexible price equilibrium, thereby restoring the first best (Smets and Wouters (2002)).

In monetary policy regimes where the short-term interest rate is the primary policy instrument, the natural rate of interest provides a measure of the stance of monetary policy. In this context, it is useful to define the natural rate of interest in terms of the real short-term ${ }^{2}$ interest rate where output

\footnotetext{
Jesus Crespo-Cuaresma (jesus.crespo-cuaresma@univie.ac.at): University of Vienna; Ernest Gnan (ernest.gnan@oenb.at) and Doris Ritzberger-Gruenwald (doris.ritzberger-gruenwald@oenb.at): Austrian National Bank. The authors would like to thank Maria-Teresa Valderrama as well as participants at an internal Austrian National Bank seminar for valuable suggestions on an earlier version of the paper. We appreciate the efficient research assistance of Elisabeth Augustin, Ernst Glatzer and Beate Resch. This is a revised version of the paper presented at the BIS Autumn 2002 Central Bank Economists' Meeting.

2 As pointed out in Laubach and Williams (2001), further advantages of using short-term, rather than bond, rates are that (i) inflation expectations are much less prone to measurement error for money market rates than for a multi-year horizon and (ii) the time preference of money and thus the term premium itself may be time-varying and would thus have to be estimated. Other studies, eg those prepared in the mid-1990s by the OECD (see Orr et al (1995) and Christiansen and Pigott (1997)) and the G10 (for a summary, see Jenkinson (1996)), addressed the evolution of long-term interest rates. These studies identified a number of economic variables (rate of return on capital and the associated level of desired investment; falling public and private savings and the level of public debt; the history of a country's inflation; and the movement of oil prices) which drive the trend change in real bond rates. However, they explained very little of the shorter-run movements, attributed by the authors to bond rates being driven by largely unobservable shifts in market expectations, including international spillovers. In addition, in the runup to EMU, expectations about future EMU participation ("convergence plays") became a major determinant for prospective
} 
converges to potential and inflation is stable (cf Bomfim (1997)). In such a setting, the natural rate of interest is seen as a medium-run "anchor" for monetary policy.

Various methods have been explored to estimate time-varying natural rates of interest (TVNRI). Several authors have developed estimated stochastic dynamic general equilibrium (SDGE) models with sticky prices and wages, within which the behaviour of the natural rate of interest and the real interest rate gap in the face of various shocks is simulated. The SDGE model for the euro area in Smets and Wouters (2002) generates a natural real rate that covaries strongly with the actual real interest rate, but is substantially more volatile. In fact, their estimated natural rate fluctuates widely between +10 and -7 during the 1990s, which appears somewhat counter-intuitive. The real interest rate gap derived from these estimates suggests that a fictitious euro area monetary policy was quite loose in the early 1990s, then turned relatively tight from 1993 onwards and became neutral to slightly expansionary from the start of EMU. However, the confidence interval around the estimates is quite wide. Therefore, the authors conclude that the scope for using the estimates of the real interest rate gap thus derived may be limited.

Laubach and Williams (2001) employed a small-scale macroeconomic model to estimate a TVNRI for the United States. By jointly estimating the natural rate of interest, potential output and the trend growth rate using the Kalman filter, they found significant variation of the natural rate of interest, driven by changes in trend growth, over the past four decades. They conclude that policymakers' mismeasurement of the NIR can substantially deteriorate macroeconomic stabilisation policy. Their estimates are shown to be sensitive to the output gap series used, and real-time estimates (with parameters, however, estimated from the entire sample) are found to perform considerably worse than "smoothed" estimates, based on the entire sample. Carrying this work further, Orphanides and Williams (2002) investigate the performance and robustness of various forms of extended Taylor-type rules in the face of an unknown degree of uncertainty about the "true" real-time values of the natural rates of unemployment and interest. As uncertainty about the unemployment gap increases, optimal policy involves far more interest setting inertia; the role of the natural rate of interest as a benchmark for policy rates diminishes sharply and converges towards zero. Instead, a "difference rule", deriving the policy rate level from its past level, the divergence of inflation from target and the change in the rate of unemployment - with no reference to the natural rates - becomes preferable. If there is uncertainty about the magnitude of misperceptions on the natural rates, they show that it is advisable to err on the side of greater uncertainty.

The present paper pursues yet another approach for estimating a time-varying natural rate of interest for the euro area, based exclusively on the statistical characteristics of the data, without imposing any conditions derived from economic theory, and aiming for a dynamic model as parsimonious as possible. Multivariate structural time series models provide a flexible framework for the dynamic specification of unobserved components (the natural rate of interest being one) and allow for exploiting the potential cross correlation across the series studied and its unobservables. Furthermore, given the fact that the general dynamic specification nests a wide variety of models, testing down to the model for which the data give more evidence can be done in a straightforward manner.

The remainder of the paper is structured as follows. Section 2 describes the data, motivates and explains the multivariate unobserved components technique, and presents a first set of estimates for the natural rate of interest and the real interest rate gap. Section 3 presents a method for constructing a risk premium adjusted three-month money market interest rate series for the euro area prior to EMU, recalculates the estimates of Section 2 with the adjusted data and interprets the resulting differences. Section 4 discusses the additional uncertainty generated by real-time estimation and the implications of relatively wide confidence bands around the estimates. Section 5 tests our TVNRI estimates for leading-indicator properties with regard to euro area inflation. Section 6 estimates feedback rules, using our TVNRI estimates, for the euro area and compares the estimates of the aggregate responses of monetary policy to changes in inflation expectations and the output gap across specifications of the pre-EMU interest rate series. Section 7 concludes.

euro area countries' bond market rates. Obviously, using short-term rates largely avoids the latter three types of complications associated with a study of long-term real interest rates. 


\section{Multivariate unobserved components estimates}

\section{$2.1 \quad$ Data}

European monetary union started just three and a half years ago, which, from an economic point of view, means that the cyclical behaviour of the euro area economy has not fully unfolded. From an econometric point of view, three and a half years do not - even with monthly data - provide a sufficient number of observations for medium-run economic analysis. Therefore, empirical work seeks to extend the time series into the past by generating synthetic aggregate euro area data. The issue is how to appropriately calculate aggregate series backwards ${ }^{3}$ as there are a number of complications and potential pitfalls which may seriously distort econometric estimates.

For our estimates, we require output, inflation and a short-term market interest rate. We approximate output by seasonally adjusted industrial production (source: Eurostat), the reason being mainly to generate more observations, due to the monthly availability of this series, as opposed to quarterly national accounts data. For inflation, we use the euro area harmonised index of consumer prices (HICP) excluding energy and unprocessed food as published by Eurostat backwards to January 1991. Taking a measure of "core inflation" is in line with the literature and aims at eliminating - to the extent possible - price disturbances not driven by demand shocks. For the short-term interest rate, we use monthly averages of the three-month money market interest rate as compiled backwards by the ECB. ${ }^{4}$

For our estimates, we consider the time period between January 1991 and March 2002 (our cutoff date for the time series), for two reasons. The first is economic: treating individual euro area countries prior to EMU as a synthetic euro area is in any event a heroic exercise. However, one can argue that with the agreement on the Maastricht Treaty in the course of $1991^{5}$ both policymakers and economic agents were gradually changing their behaviour, well ahead of the start of the third stage of EMU, towards a single monetary area. In a sense, the regime change implied by EMU did not occur abruptly but was absorbed gradually as the various provisions of the Maastricht Treaty successively entered into force and as expectations adjusted to the prospect of countries joining EMU. Exchange rate stability and monetary and financial integration were regarded by policymakers as a primary goal of monetary and economic policies, and fiscal consolidation moved centre stage from the mid-1990s, both with a view to monetary union. Price stability had become generally accepted in EU policy circles as the central banks' primary goal, and EU central banks were, in the course of the 1990s, granted far-reaching independence. Furthermore, the early 1990s marked the entering into force of the Single Market Programme, which fostered economic integration. Taken together, these developments set the 1990s clearly apart, in terms of economic integration and policy consensus, from earlier periods. The second reason for limiting our estimates to the 1990s is the availability of data: the HICP as calculated backwards by Eurostat reaches back to 1991 only.

Inspection of the raw data (Graph 1) reveals the following main features: euro area industrial production fell by close to $10 \%$ during the recession of 1992-93, then followed a more or less continuous upward path until 2000 but declined from 2001 onwards, reflecting the recent economic downturn. Core inflation followed a clear downward trend in the course of the 1990s, falling from around $4 \%$ in the early 1990 s to around $1 \frac{1}{2} \%$ by the start of EMU; it recovered somewhat to around $21 / 2 \%$ by spring 2002. Both nominal and real (ex ante) three-month money market interest rates started

3 This question has been addressed extensively in various official fora (inter alia, Eurostat and the European Monetary Institute/ECB) before the start of EMU.

4 The ECB computes euro area three-month money market rates prior to 1999 from national data, using PPP-adjusted GDP weights (base year: 1995). We also considered a series from Reuters, which uses ECU money market rates prior to 1999. The two series differ considerably, the reasons being, inter alia, that the ECU currency basket did not coincide 1:1 (in terms of both currency basket range and weights) with the currencies included in the euro from 1 January 1999, and that the ECU market rate at times diverged - for various reasons - substantially from its theoretical value (defined as the weighted average of the rates of its basket currencies). For these conceptual weaknesses of the ECU-based series, we opted for the ECB aggregate three-month money market series (monthly averages).

5 The key ingredients of the Maastricht Treaty became clear in the course of 1991, although the Treaty was only signed in February 1992 and entered into force in late 1993. 
Graph 1

Economic indicators in the euro area

Three-month nominal interest rate

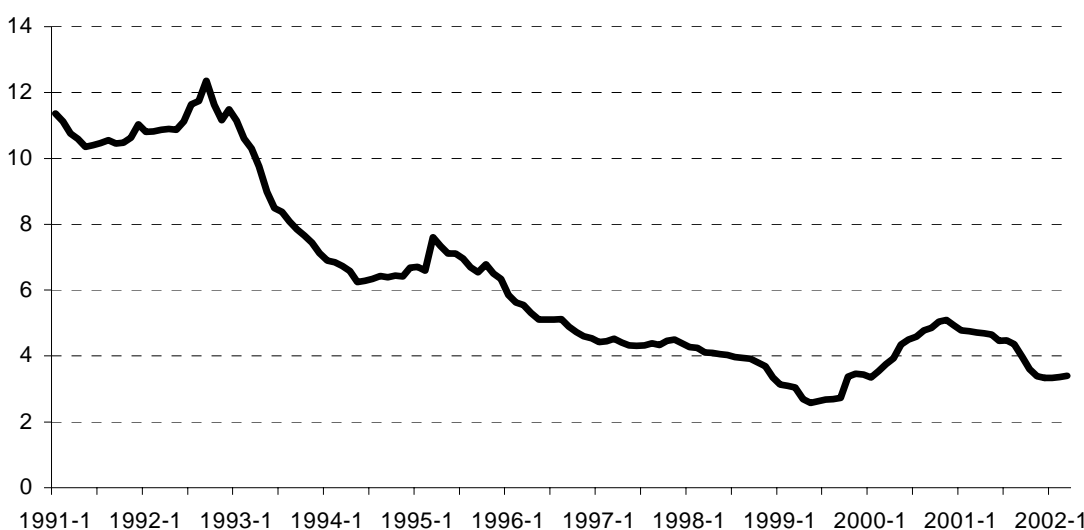

Real interest rate

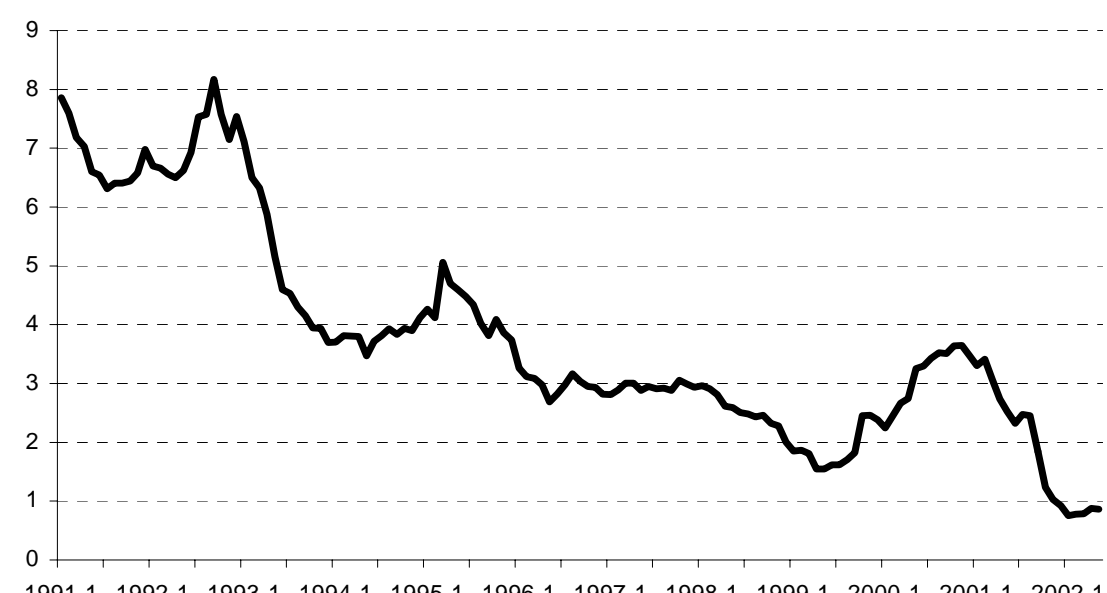

1991-1 1992-1 1993-1 1994-1 1995-1 1996-1 1997-1 1998-1 1999-1 2000-1 2001-1 2002-1 Sources: ECB; Eurostat.
Industrial production index

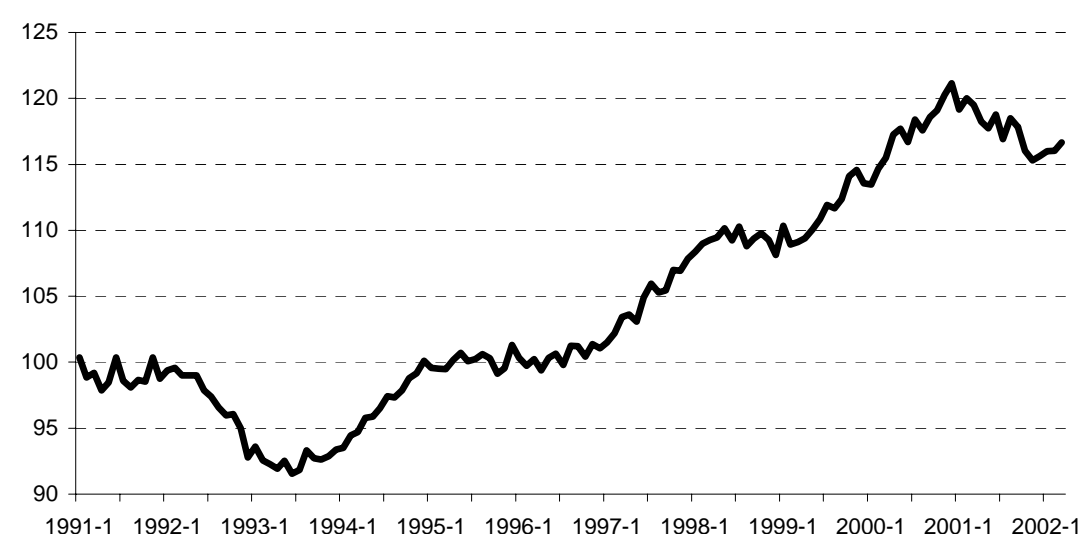

Core inflation

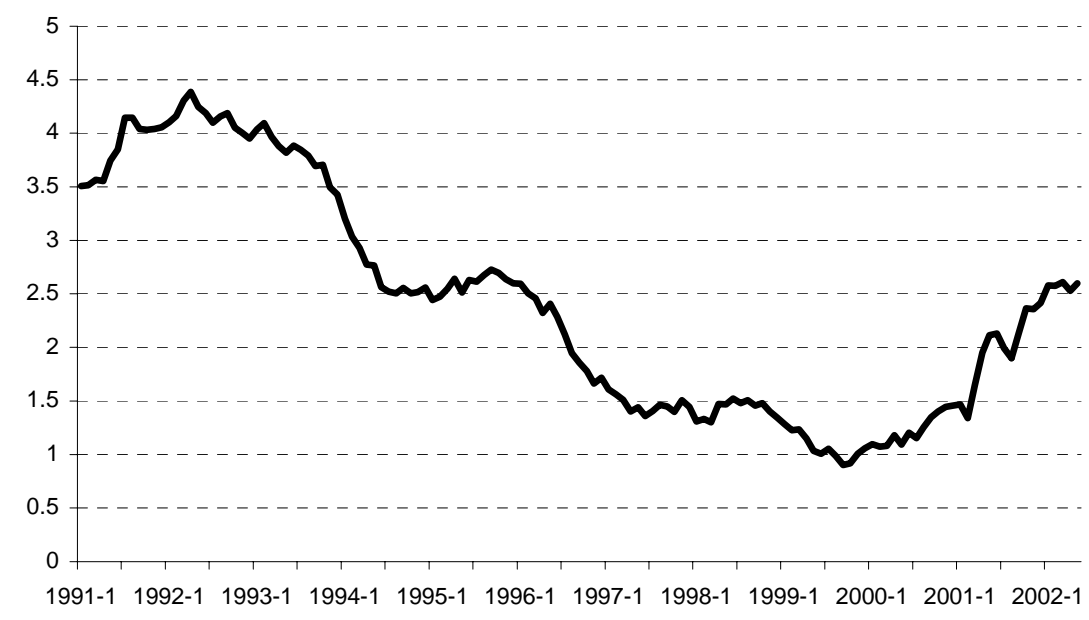


from very high levels in the early 1990s and followed a strong general downward trend throughout the 1990s. The peaks around 1992 and 1995 reflected the tensions prevailing in the exchange rate mechanism (ERM) of the European monetary system (EMS). Between mid-2000 and mid-2001 the Eurosystem kept short rates high to combat rising inflationary pressures.

\subsection{Specification of the multivariate unobserved components model}

In the spirit of the methodology developed mainly in Harvey (1989), we specify a multivariate unobserved components model in order to extract the trend component of the ex ante real interest rate. Consider the vector $z_{t}=\left(\begin{array}{lll}r_{t} & y_{t} & \pi_{t}\end{array}\right)^{\prime}$ composed of real interest rates $\left(r_{t}\right),{ }^{6}$ (logged) industrial production $\left(y_{t}\right)$ and inflation $\left(\pi_{t}\right)$. We are interested in decomposing $z_{t}$ into a trend component, a cyclical component and an irregular component in an additive fashion, such that:

$z_{t}=\mu_{t}+\phi_{t}+u_{t} ; \quad u_{t} \sim \operatorname{NID}\left(0, \Sigma_{u}\right)$

where $\mu_{t}$, the multivariate trend component, is assumed to follow a (multivariate) random walk with drift, where the drift itself follows a random walk, that is:

$\mu_{t}=\mu_{t-1}+\kappa_{t-1}+\tau_{t} ; \quad \tau_{t} \sim \operatorname{NID}\left(0, \Sigma_{\tau}\right)$

$\kappa_{t}=\kappa_{t-1}+\psi_{t} ; \quad \psi_{t} \sim \operatorname{NID}\left(0, \Sigma_{\psi}\right)$

The errors in the specification of the trend, $\tau_{t}$ and $\psi_{t}$, are assumed to be mutually uncorrelated and uncorrelated with $u_{t}$. The cyclical component is specified as a sine-cosine wave with time-evolving parameters:

$$
\left(\begin{array}{c}
\phi_{t} \\
\phi_{t}^{*}
\end{array}\right)=\rho\left[\left(\begin{array}{cc}
\cos \lambda & \sin \lambda \\
-\sin \lambda & \cos \lambda
\end{array}\right) \otimes I\right]\left(\begin{array}{c}
\phi_{t-1} \\
\phi_{t-1}^{*}
\end{array}\right)+\left(\begin{array}{c}
\omega_{t} \\
\omega_{t}^{*}
\end{array}\right)
$$

where $\left(\omega_{t} \omega_{t}^{*}\right)^{\prime} \sim \operatorname{NID}\left(0, I \otimes \Sigma_{\omega}\right), \rho \in(0,1)$ and $\lambda \in(0, \pi)$. The error in the cyclical component is furthermore assumed to be uncorrelated with the errors in the other components. The cyclical frequency, $\lambda$, and the cycle damping factor, $\rho$, are thus assumed to be equal across variables.

The structural time series model described above is able to exploit the common statistical features of the series to be studied simultaneously by allowing correlation across the individual error processes in a given unobserved component. The estimation of the parameters of interest can be carried out using maximum likelihood methods after setting the prediction error decomposition using Kalman filtering (for details, see Harvey (1989)). The state-space representation of the multivariate structural model described above is given by:

$z_{t}=F \alpha_{t}+u_{t}$

$\alpha_{t}=T \alpha_{t-1}+\varepsilon_{t}$

where the state vector is given by $\alpha_{t}=\left(\mu_{t}^{\prime} \kappa_{t}^{\prime} \phi_{t}^{\prime} \phi_{t}^{* \prime}\right)^{\prime}$ and the disturbance vector of the state equation is given by $\varepsilon_{t}=\left(\tau_{t}^{\prime} \psi_{t}^{\prime} \omega_{t}^{\prime} \omega_{t}^{* \prime}\right)^{\prime}$. The matrices associated with the state space representation are:

$$
\begin{aligned}
F & =\left(\begin{array}{llll}
I & 0 & I & 0
\end{array}\right) \\
T & =\left(\begin{array}{cccc}
I & I & 0 & 0 \\
0 & I & 0 & 0 \\
0 & 0 & \rho \cos \lambda I & \rho \sin \lambda I \\
0 & 0 & -\rho \sin \lambda I & \rho \cos \lambda I
\end{array}\right)
\end{aligned}
$$

\footnotetext{
6 We use ex ante real interest rates, defined as the prevailing interest rate in period $t$ minus the inflation rate between period
} $t-1$ and $t$. This implies that the monetary authority assumes that inflation follows a random walk. 
Given the state-space representation, Kalman filtering methods allow the computation of the likelihood function by means of the one-step-ahead prediction error decomposition and therefore the estimation of the hyperparameters of interest (the cyclical frequency, $\lambda$, the cycle damping factor, $\rho$, and the variance-covariance matrices of the unobservable disturbances). ${ }^{7}$

Furthermore, the prediction error decomposition enables us to retrieve the "smoothed" and "filtered" estimates of the unobservable states. The smoothed unobserved states are just $\alpha_{t}^{s}=E\left(\alpha_{t} \mid\left\{z_{t}\right\}_{t=0}^{T}\right)$,

while the filtered states are $\alpha_{t}^{f}=E\left(\alpha_{t} \mid\left\{z_{t}\right\}_{t=0}^{t}\right)$. That is, the smoothed estimates exploit the information contained in the whole sample, while the filtered estimates form conditional expectations on the unobservable state at time $t$ using information up to $t-1$. The filtered estimates will be also referred to as "real-time" estimates. The specification of a smooth trend in the multivariate unobserved components model (which implies that the trend component does not contain the error term $\tau_{t}$ ) improved the fit significantly and was therefore imposed for the estimation using euro area data.

Notice that the identification - in economic terms - of the TVNRI (and of potential output as well as equilibrium inflation) is based on the notion that the estimated cyclical component should correspond to the business cycle. The starting values for the parameters of the cycle in the optimisation algorithm were thus specified to lie at intervals corresponding to plausible business cycle frequencies and persistence. $^{8}$ The three trends extracted by means of this estimation procedure can be interpreted as potential output, trend inflation and the (time-varying) natural rate of interest.

\subsection{Estimation results}

The estimation of the multivariate unobserved components model using the original nominal interest rate dataset isolates a cycle with a frequency, $\lambda$, of 0.18 radians, corresponding to a cyclical period of around three years. The estimated damping factor, $\rho$, for the cycle is 0.97 , a result that matches the range of cyclical persistence of economic variables reported in the literature (see, for example, Harvey and Jaeger (1993)). While the residuals present no significant first-order autocorrelation (as measured by the Durbin-Watson test statistic) for any of the series included in the multivariate specification, the residuals from the real interest rate series reject the null hypothesis of normality for the Jarque-Bera test at any reasonable significance level. ${ }^{9}$

Graph 2 shows the estimated natural rate of interest in the upper left-hand panel. The natural rate reflects the trend of the actual real rate, which is strong but gradually flattening over the 1990s. Since the start of EMU, the behaviour of the natural rate is rather flat, slightly above $2 \%$. The TVNRI contrasts sharply against a fixed estimate based on the simple sample average of $3.8 \%$.

The amplitude of the output gap (Graph 2, upper right-hand panel) is considerably smaller than that resulting from Hodrick-Prescott filtering industrial production series. This feature has been widely documented in the literature (see, for example, Harvey and Jaeger (1993) or Cogley and Nason (1995)) and seems to be due to the fact that the Hodrick-Prescott filter tends to isolate spurious cycles.

\footnotetext{
Notice that Hodrick-Prescott (HP) filtering (Hodrick and Prescott (1997)) appears as a special case of a univariate unobserved components model where the variable of interest, in our case the ex ante real interest rate, is decomposed into a smooth trend and an irregular component, where the variances of both components are linked by a smoothing parameter, $q$. The resulting (univariate) unobserved components model is:

$r_{t}=\mu_{t}+u_{t} ; \quad u_{t} \sim \operatorname{NID}\left(0, \sigma_{u}\right)$

$\mu_{t}=\mu_{t-1}+\kappa_{t}$

$\kappa_{t}=\kappa_{t-1}+\psi_{t} ; \quad \psi_{t} \sim \operatorname{NID}\left(0, q \sigma_{u}\right)$

where $q$ is usually set to $1 / 14,400$ for monthly data. The HP trend is the smoothed estimate of $\mu_{t}$, and the filtered series results from subtracting the smoothed trend from the original series.

8 Starting values for the cyclical frequency $\lambda$ were set such that the corresponding cyclical period lies between three and five years, and the $\rho$ parameter was initiated at values ranging between 0.80 and 0.99 . The estimated parameters were robust to the choice of starting values for $\lambda$ and $\rho$ in this range. An unreasonably short-lived cycle was isolated if the starting values of $\lambda$ were chosen to be too large.

9 For detailed results of the estimation of the structural time series models, see the Appendix.
} 
Graph 2

Multivariate unobserved components model: estimation results

Real interest rate and time-varying natura rate of interest (smoothed estimate)

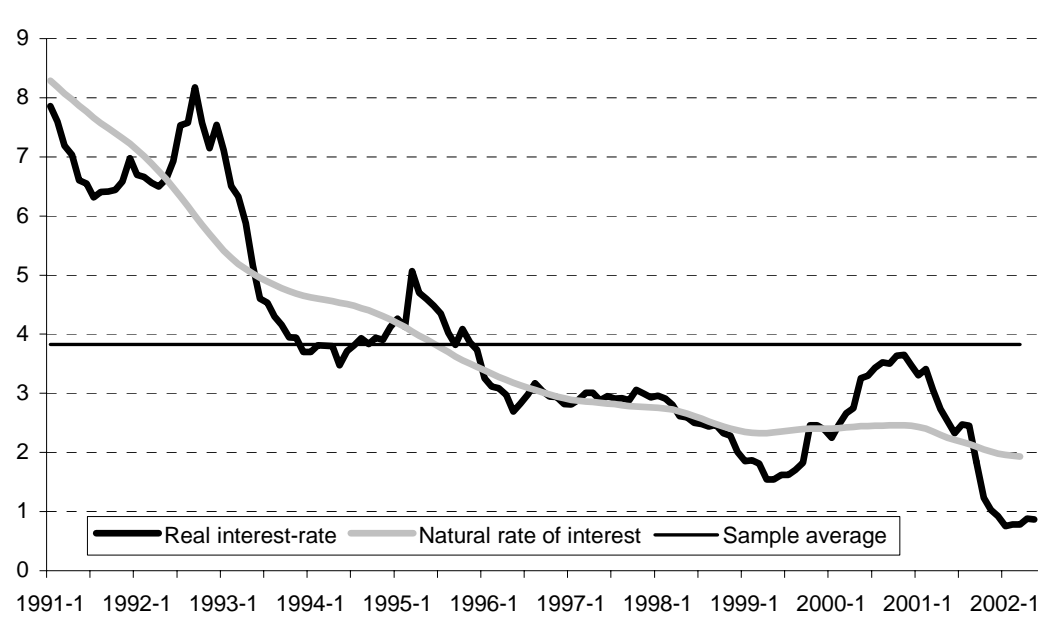

Real interest rate gap

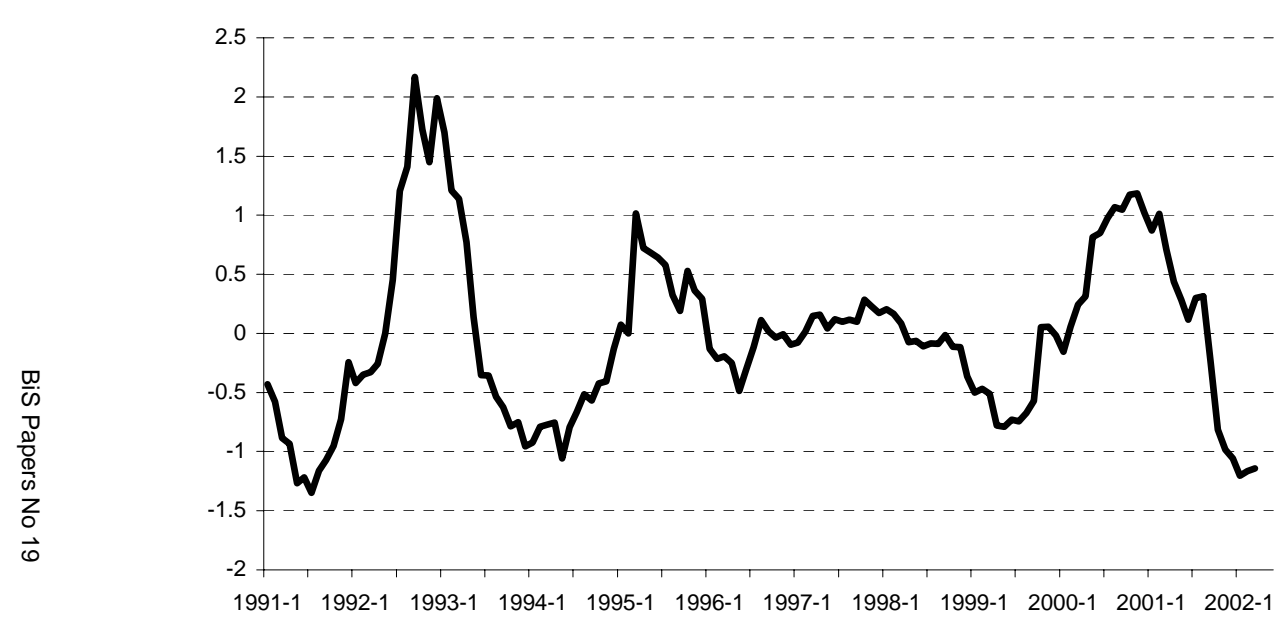

Output gap

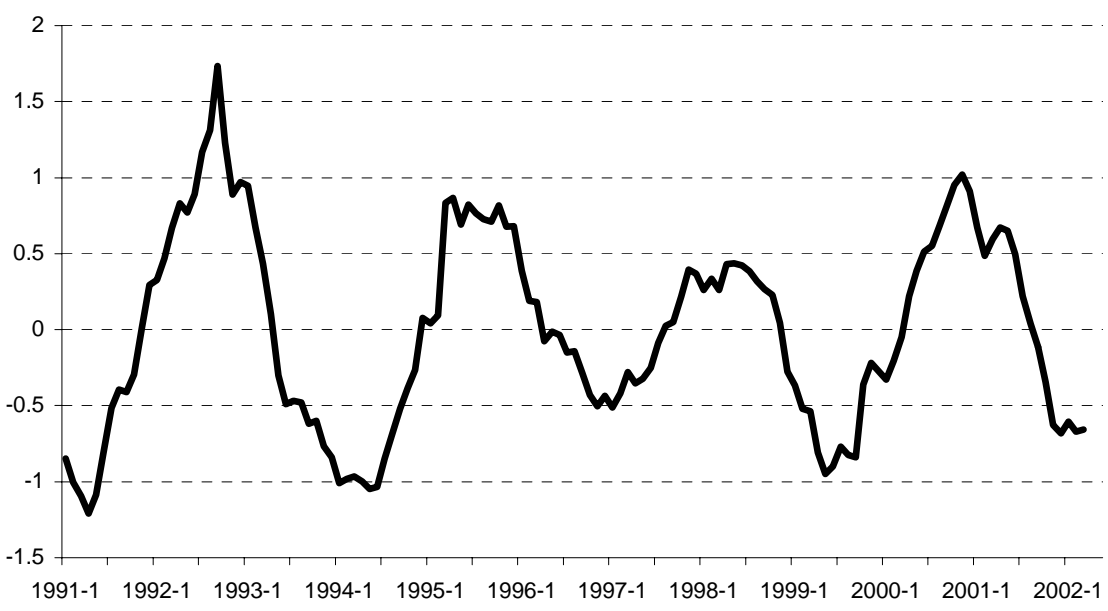

Core inflation gap

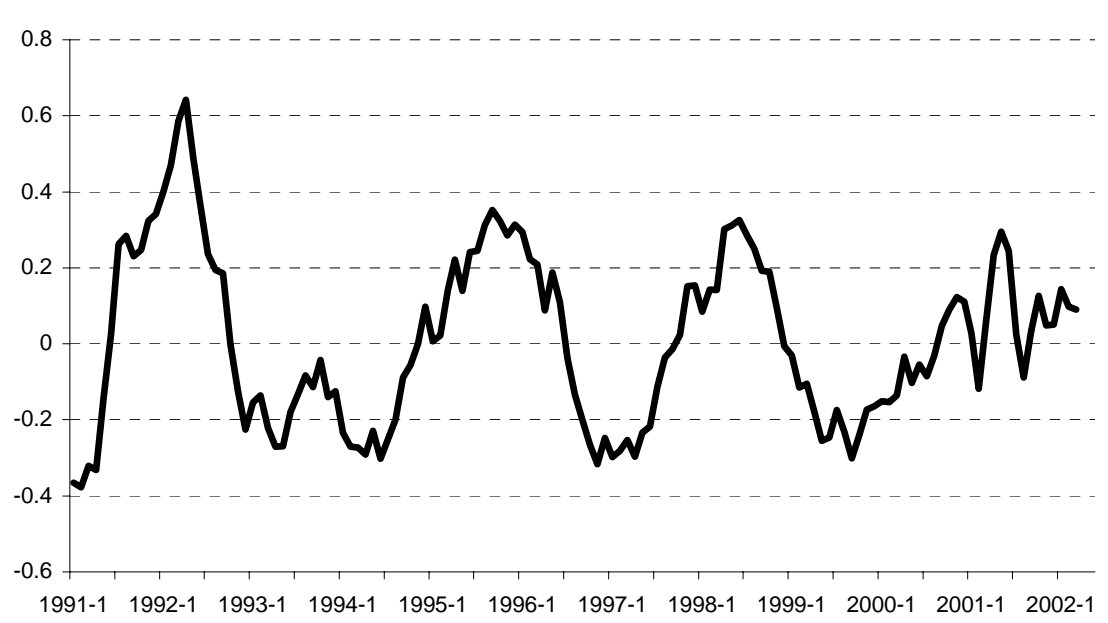


The real interest rate gap (Graph 2, lower left-hand panel), ie the difference between the actual and timevarying natural real interest rates, broadly mirrors the estimated evolution of the output gap. According to this measure, monetary policy was rather tight in late 1992 and early 1993, and less so in 1995 and 2000. It was loose in 1991, 1993-94, 1999 and from late 2001 onwards. A real interest rate gap based on the simple sample average yields a sharply different assessment: according to such a measure, monetary policy would have been mostly restrictive up to the mid-1990s and consistently expansionary thereafter.

\section{Adjusting for risk premia prior to EMU}

One major feature of the above estimates was a very high TVNRI in the first half of the 1990s and a much lower level subsequently. We suspect that the high level of rates in the first half of the 1990s is (at least partly) attributable to risk premia linked to the exchange rate tensions within the ERM and unsustainable fiscal positions prior to EMU. If the aim is to estimate a TVNRI and a derived real interest rate gap suitable for monetary policy analysis in EMU, risk premia which no longer exist in the new regime of EMU should be excluded from the estimation. These risk premia would be expected to include exchange rate risk premia (as experienced on various occasions within the ERM of the EMS) and default risk premia to the extent that they may have been reduced by the Stability and Growth Pact. In other words, we seek to generate a TVNRI exclusively driven by output and inflation. ${ }^{10}$

Both of the euro area money market series considered in Section 3 (ECB aggregated euro area series; $\mathrm{BIS} /$ Reuters ECU money market series) prior to 1999 can be assumed to include exchange rate driven, fiscal policy related and other risk premia. We therefore develop a method to eliminate these risk premia from national nominal money market rates, which we in turn use to construct a new, risk-adjusted synthetic time series for aggregate euro area three-month money market rates prior to 1999.

In our model, the risk premium on each national money market rate is defined to be the part of the (nominal) interest rate spread with the German short term-interest rate that cannot be explained by differentials in inflation expectations and/or business cycle desynchronisation. The adjustment of the series is done as follows. First, the risk premium (which need not be assumed to be constant through time) is extracted for each country. Given the working definition of the interest rate risk premium above, the interest rate spread with Germany is regressed on the output gap differential between the country of interest and Germany and the inflation forecast differential. That is, for country $k$ :

$$
s_{t}^{k}=\beta_{0}+\beta_{1}\left(g_{t}^{k}-g_{t}^{G E R}\right)+\beta_{2}\left[E\left(\pi_{t+12}^{k} \mid\left\{\pi_{s}^{k}\right\}_{s=1}^{t}\right)-E\left(\pi_{t+12}^{G E R} \mid\left\{\pi_{s}^{G E R}\right\}_{s=1}^{t}\right)\right]+\gamma_{t}
$$

where $s_{t}^{k}$ is the interest rate spread between country $k$ and Germany, $g_{t}^{k}$ is the output gap ${ }^{11}$ of country $k$, the inflation forecasts are obtained by computing the conditional expectation after fitting an autoregressive process ${ }^{12}$ to the inflation data ranging up to period $t, \gamma_{t}$ is assumed to be a random shock and $E(\cdot)$ is the expectation operator.

After estimating equation (7), the original series of nominal interest rates $\left(i_{t}^{k}\right)$ are adjusted by subtracting the estimated constant and the residuals from the estimation. The adjusted series is thus:

$$
i_{t}^{a d j, k}=i_{t}^{k}-\hat{\beta}_{0}-\hat{\gamma}_{t}
$$

Given the potential correlation between the error and the regressors (in the sense of correlation between inflation expectations and the exchange rate driven risk premium, for instance), lags ranging between six and 12 months of the output gap and inflation differentials were used as instruments in

10 We abstract from modelling other general factors driving real interest rates, such as time preference parameters.

11 The output gap series used for each country corresponds to the cyclical component of industrial production resulting from estimating a multivariate unobserved components model using data on real interest rates, inflation and industrial production.

12 The lag length of the autoregressive process that is fitted to the inflation data is chosen to be the one that minimises the Akaike Information Criterion for the data available at each time point $t$. The lag length is thus revised with each realisation of inflation, so as to model changes in the persistence of inflation through time. In all cases the range of lags taken into account for the choice was between one and 12 . 
the estimation of equation (7). Durbin-Wu-Hausman tests and Sargan tests confirm both the need for instruments and the validity of the instruments used. The only exception is Portugal, where DurbinWu-Hausman indicated that no instrumental variable estimation was necessary and ordinary least squares (OLS) estimation was used. The source of national data is the BIS for the national money market rates and Eurostat for inflation and industrial production. Incomplete datasets for Portugal and Finland were augmented using data from the Bank of Portugal and the Bank of Finland, respectively.

\section{Graph 3}

\section{Interest rate risk premium and unadjusted and risk-adjusted} real interest rates

Interest rate risk premium (euro area aggregate)

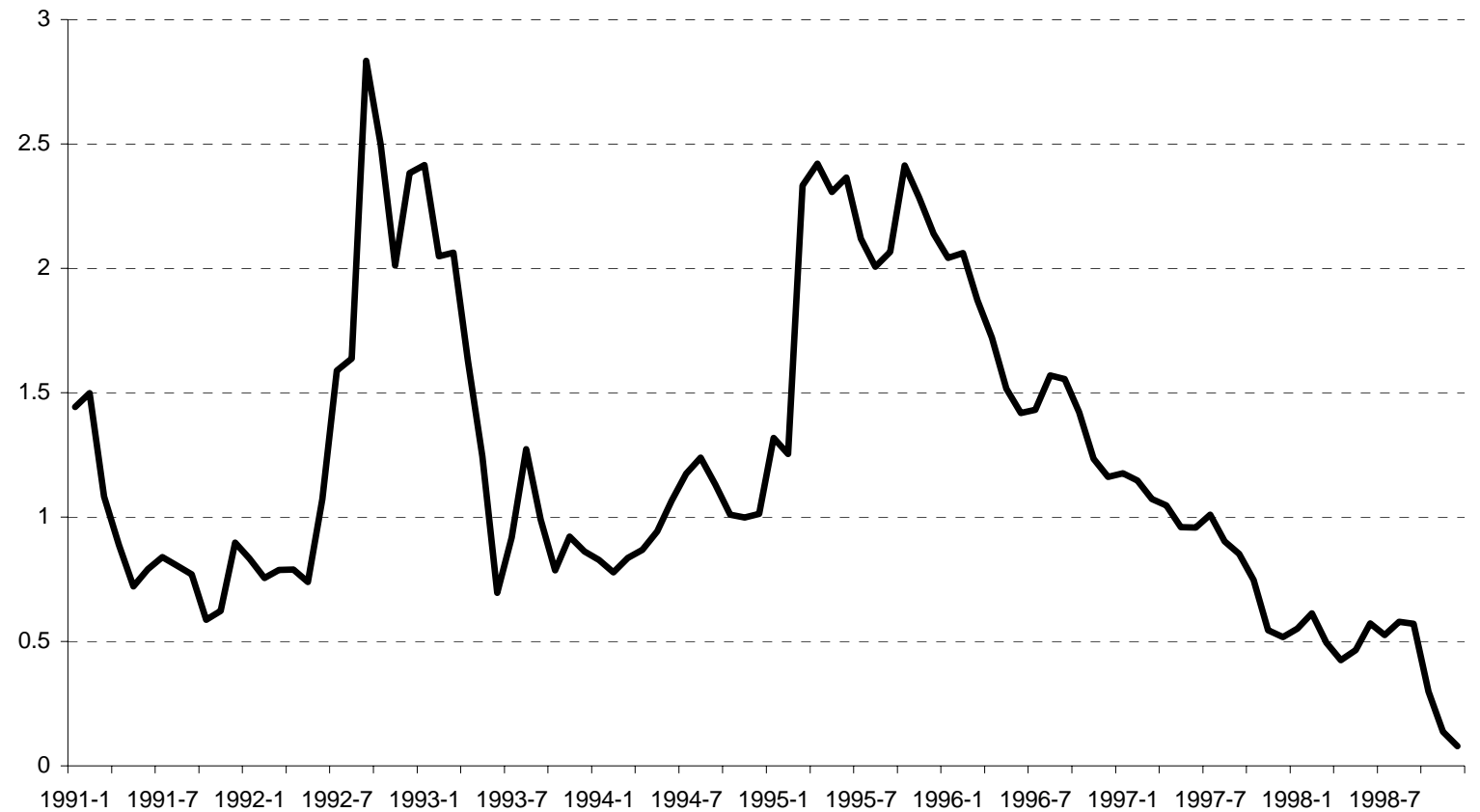

Real interest rates

Unadjusted $\quad$ Risk adjusted

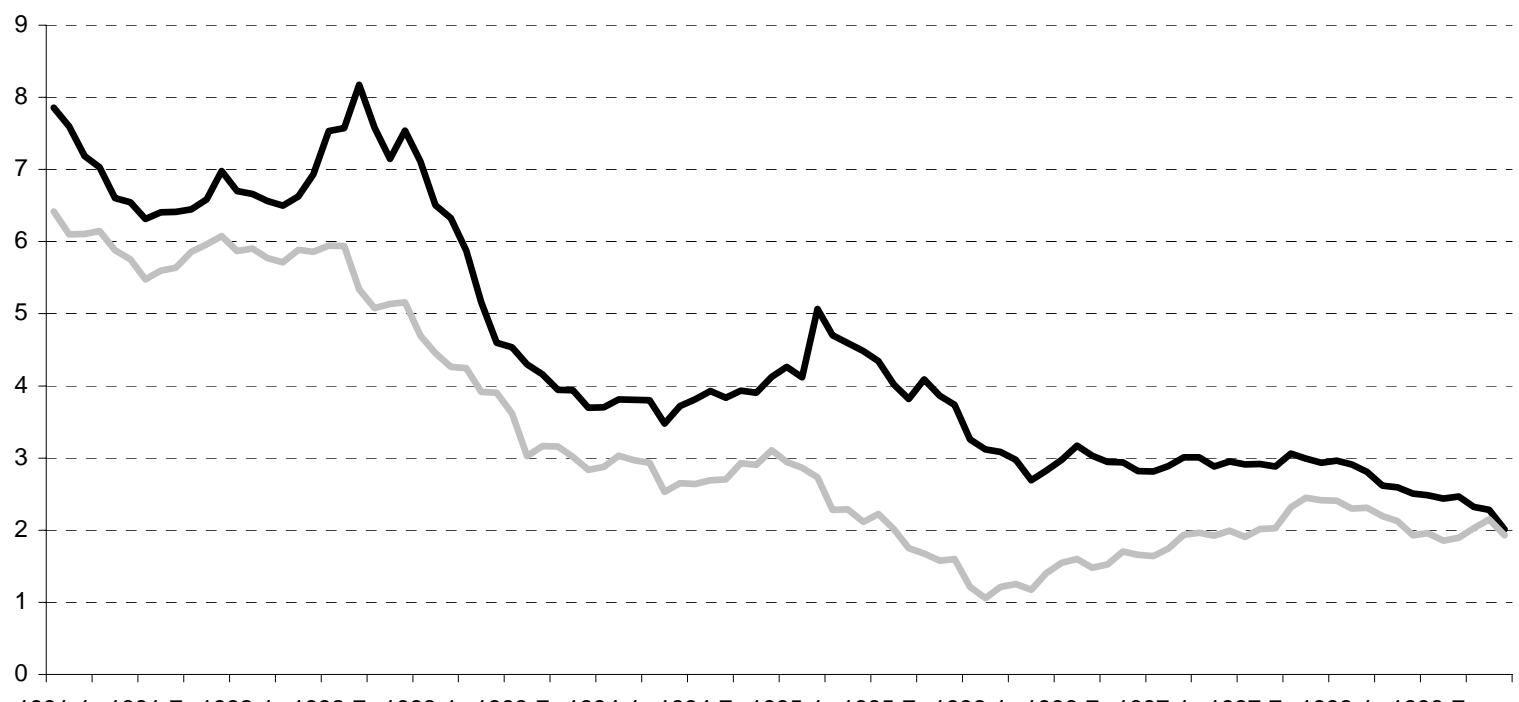

1991-1 1991-7 1992-1 1992-7 $1993-1 \quad 1993-7 \quad 1994-1 \quad 1994-7 \quad 1995-1 \quad 1995-7 \quad 1996-1 \quad 1996-7 \quad 1997-1 \quad 1997-7 \quad 1998-1 \quad 1998-7$ 
The upper panel of Graph 3 shows the estimated aggregated risk premium for the countries of the euro area prior to 1999 , revealing the suspected high risk premia of up to $2 \frac{1}{2} \%$ and more around the ERM crisis of 1992-93 and the exchange rate tensions of 1995. It also shows that, as to be expected, the risk premia virtually vanished until the end of 1998. The lower panel of Graph 3 compares the adjusted three-month real interest rate for the euro area ${ }^{13}$ with the original unadjusted series. For background information, Graph 4 shows the estimated national interest rate risk premia. ${ }^{14}$

\section{Graph 4}

\section{National interest rate risk premia}
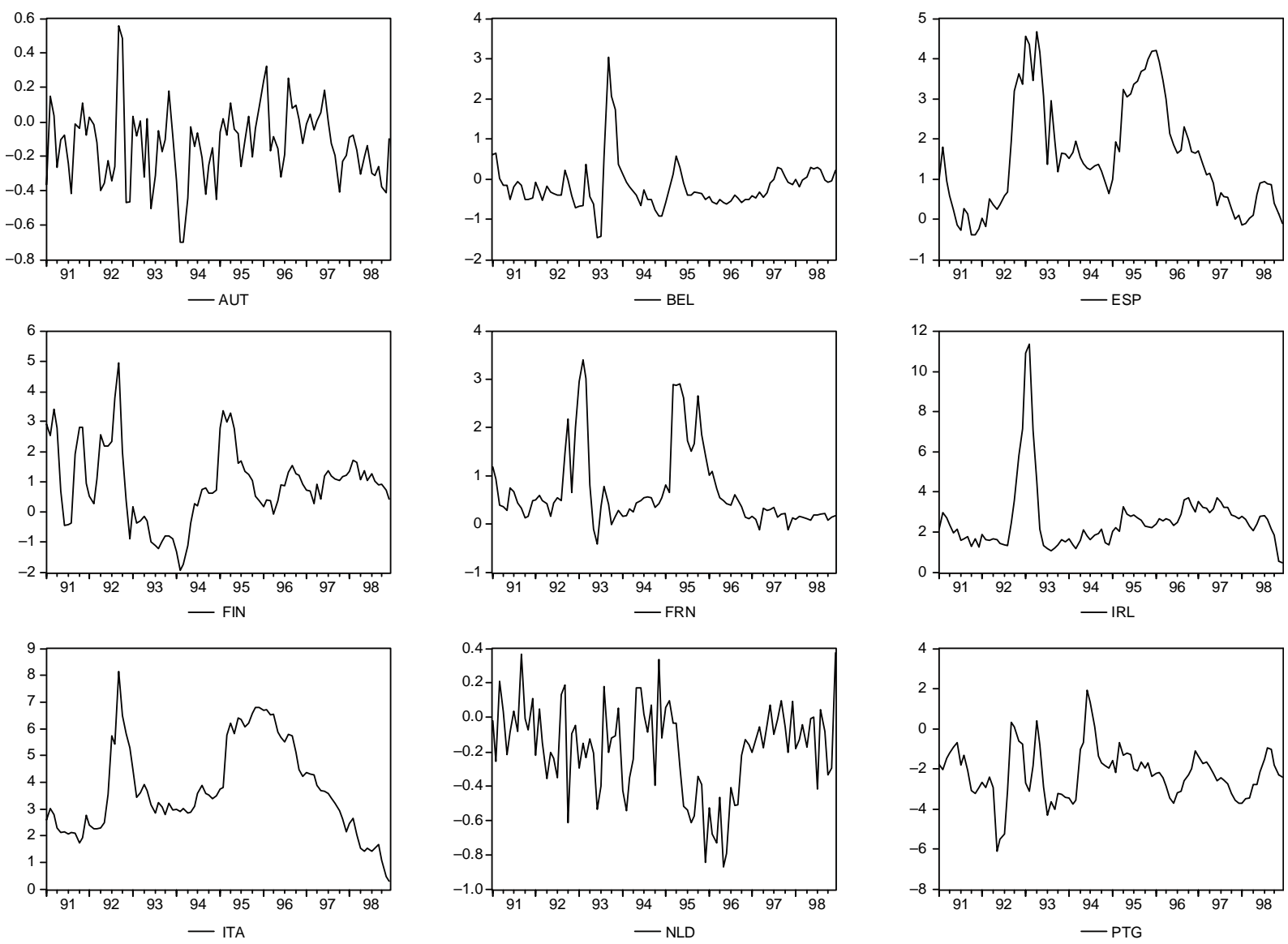

Using the risk-adjusted euro area three-month money market series, we re-estimate the TVNRI. The cyclical frequency estimated for the multivariate unobserved components model with the adjusted interest rate series is 0.11 radians, which corresponds to a cyclical period of around four and a half years. None of the residual series presents significant first-order autocorrelation, and the null of normal distribution of the residuals cannot be rejected at the $5 \%$ significance level for any of the series.

The risk-adjusted natural rate of interest is shown in the upper panel of Graph 5. Leaving aside the start of the estimate, the natural rate fluctuates between $1 \frac{1}{2}$ and $31 / 4 \%$ between 1994 and now. The average of the real interest rate over the sample period at slightly below $3 \%$ is much lower and more in line with rule of thumb estimates. Compared to the risk-unadjusted estimates, the TVNRI now traces

13 The aggregation has been done using weights based on the relative GDP (at PPP prices) of each country in the EMU aggregate. The relative GDP data are annual, so they are left unchanged across months in a given year.

14 Remember that, given our definition of the interest rate risk premium, only premia relative to Germany are taken into account. Therefore, the aggregated series may still contain extra (potentially time-varying) risk premia with respect to the rest of the world that need not be symmetrical across countries. 
the actual real market rate more closely, its cyclical behaviour is far more pronounced; as a corollary to this, the real interest rate gap fluctuates less now.

\section{Graph 5}

Adjusting for risk premia: interest rate results

Risk-adjusted real interest rate and time-varying natural rate of interest (smoothed estimate)

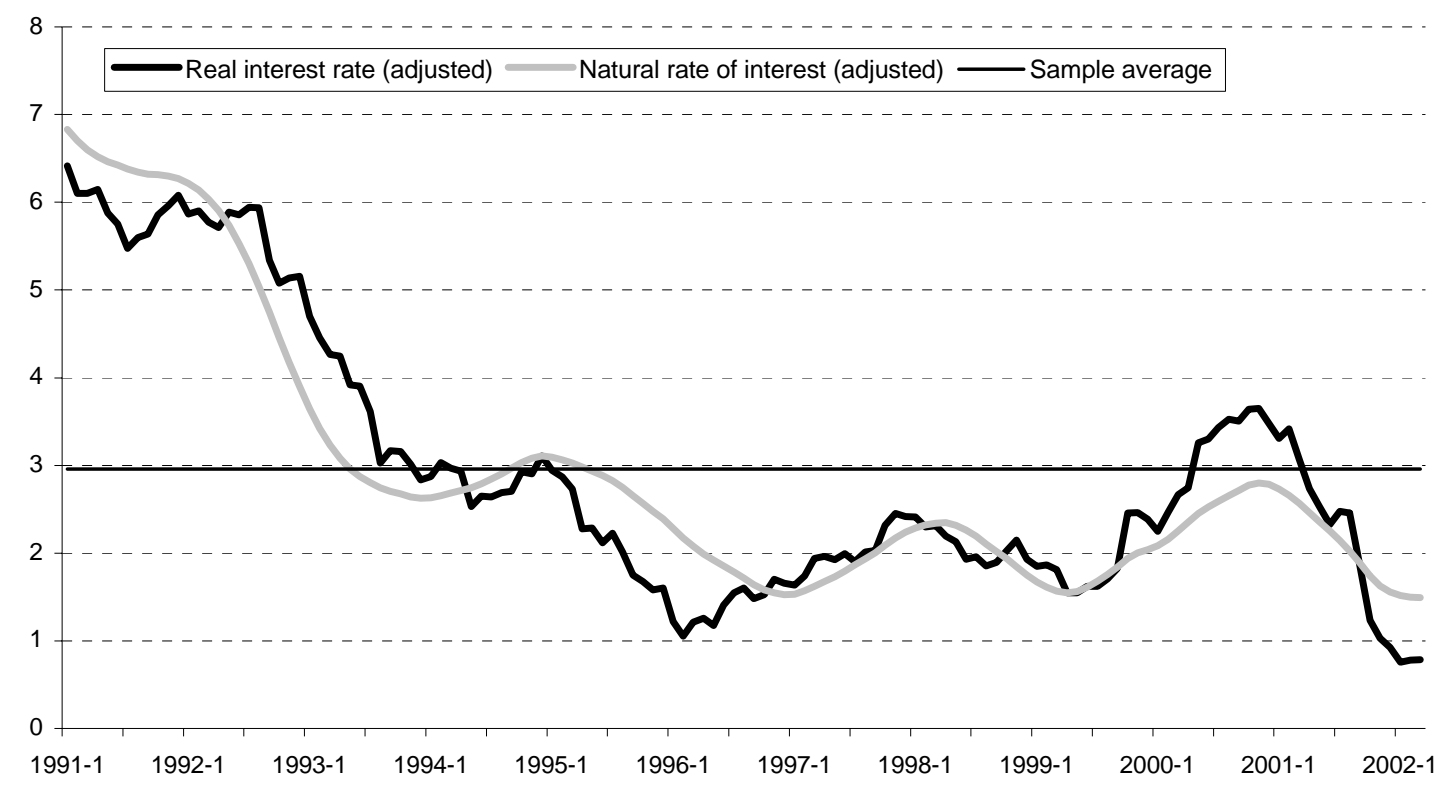

Real interest rate gap; risk-adjusted and unadjusted

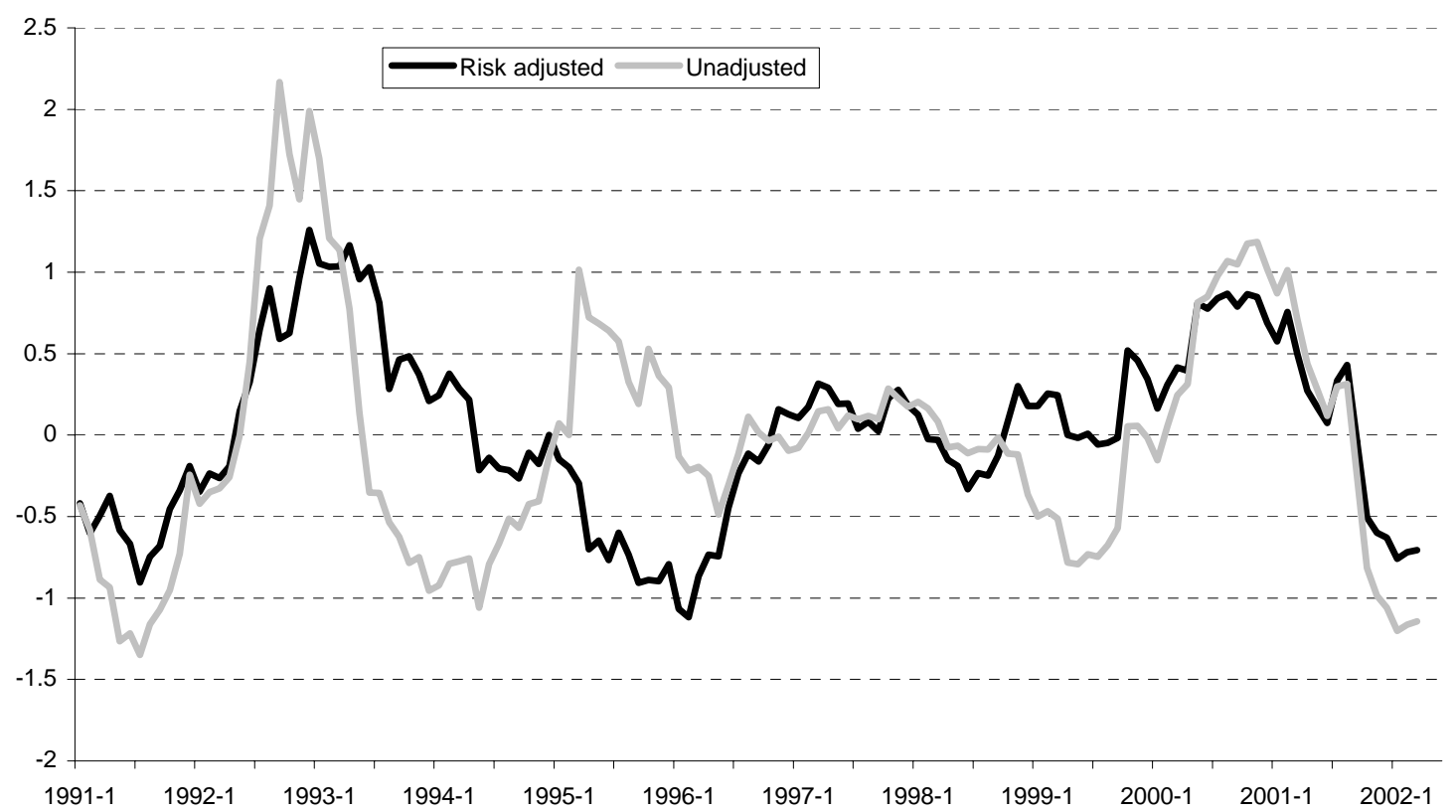

Comparing the risk-adjusted and unadjusted real interest rate gaps (see lower panel of Graph 5) reveals substantial differences in the first half of the 1990s, but also non-negligible differences, particularly in 1999 (up to 80 basis points) and 2000 and 2002 (30-40 basis points each). In several instances (1993-94, 1995-96, 1999), even the sign of the risk-adjusted real interest rate gap estimate is opposite to the unadjusted one. In other words, the risk-adjusted real interest rate gap and the unadjusted one would have yielded opposite monetary policy advice during these periods. Contrary to 
the unadjusted estimate, euro area monetary policy is now no longer qualified as expansionary in 1999 and is also considered less expansionary in 2002. On the other hand, the adjusted real interest rate gap suggests a lesser degree of restrictiveness during the upswing in 2000-01. More generally, the adjusted estimates suggest smoother and more cautious changes in the Eurosystem's policy stance.

\section{Real-time estimates and confidence bands}

For practical monetary policy purposes, estimates of the natural rate need to be done "real-time", ie on the basis of data available only up to the point in time where the monetary policy decision is taken. As new data become available, the original estimates are continuously revised reflecting the richer information set available. Graph 6 shows the divergence between real-time estimates ("filtered") and those based on the entire sample ("smoothed") since the start of EMU. ${ }^{15}$ The panel below is based on the unadjusted interest rate series; the panel at the top of the following page uses the risk-adjusted money market series as derived in Section 3. The real-time estimation error reaches up to $1 / 2$ percentage point for both series. This is also reflected in the real interest rate gaps derived from these four natural-rate series (Graph 7). Our estimates confirm the finding pointed out in the literature (see, for example, Orphanides (2001), Orphanides and Williams (2002) and Laubach and Williams (2001)) that policy rules based on unobserved macroeconomic variables, such as the natural rates of output, unemployment or interest - or the derived "gaps" - involve a substantial margin of error if applied "realtime" and should thus be used cautiously.

\section{Graph 6}

\section{Filtered and smoothed TVNRIs, unadjusted and risk-adjusted data} Unadjusted

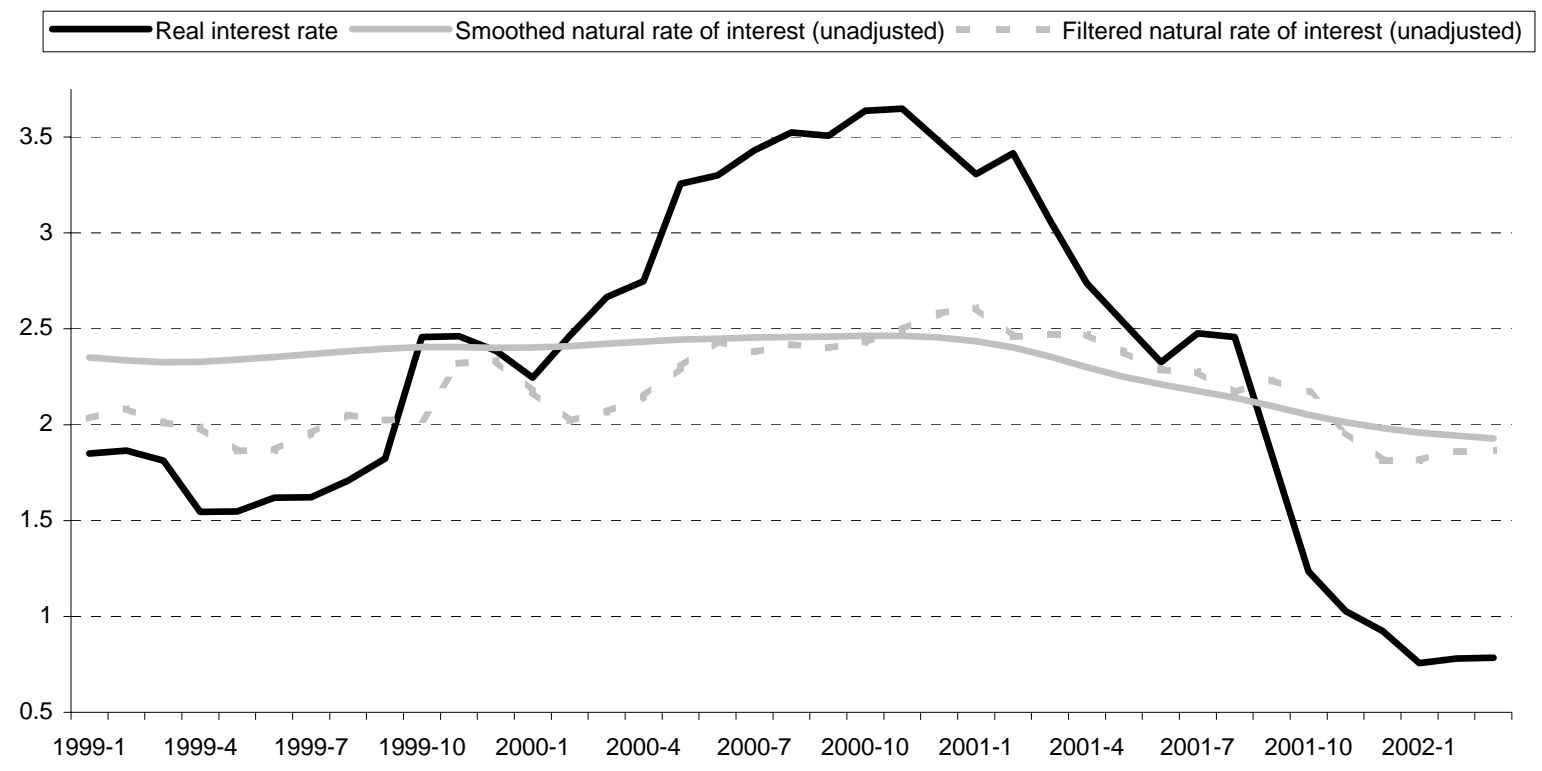

15 We abstain from showing and interpreting the - even bigger - divergences for the period before 1999 since the number of data points available for these real-time estimates becomes quite small, given our initial choice of investigating only data starting from January 1991. 
Graph 6 (cont)

Risk adjusted

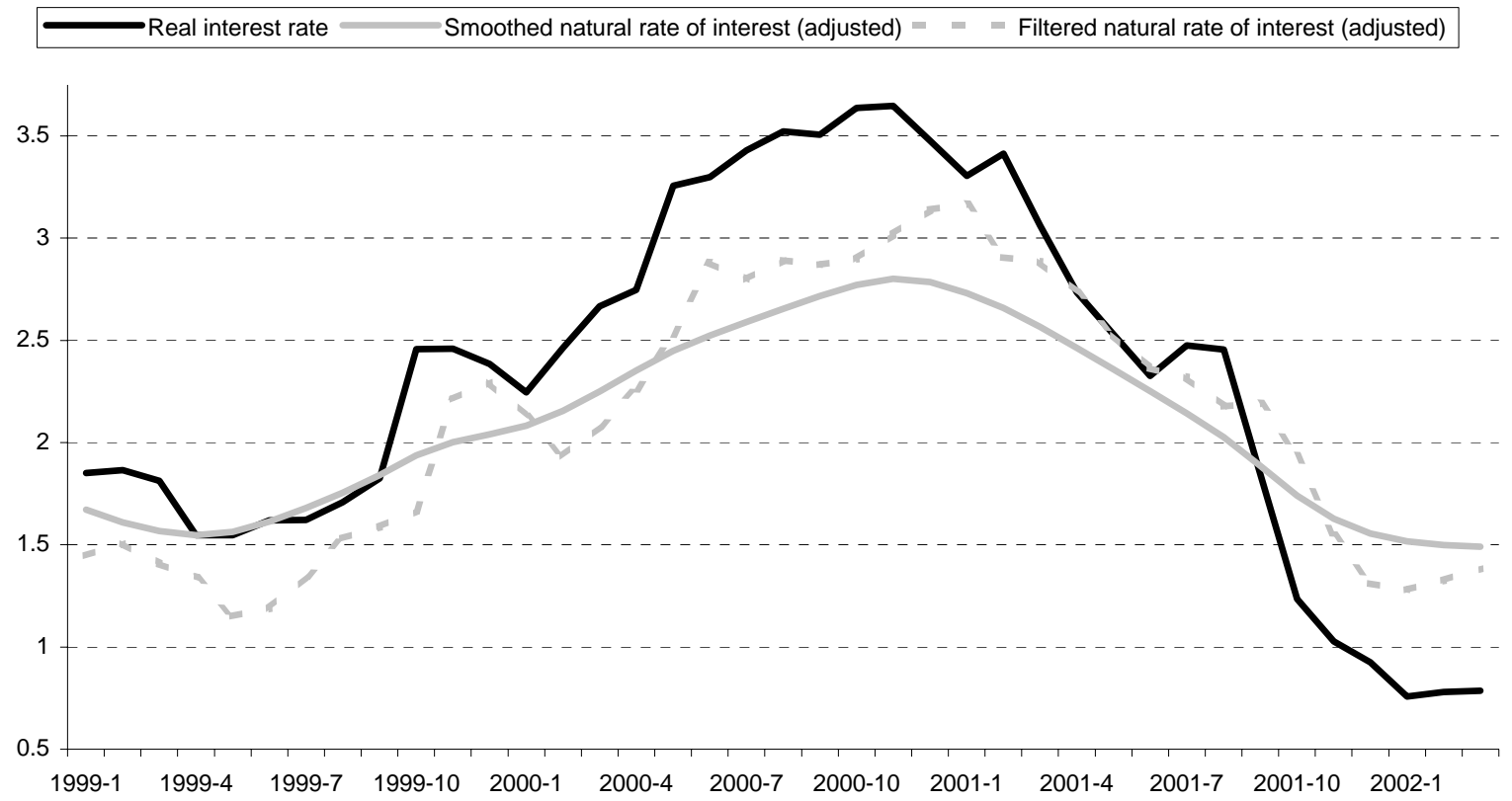

However, even the smoothed series, based on the full-sample estimates, suffer from substantial uncertainty, as shown in Graph 8 . Wrapping a 75\% confidence band around our estimates of the TVNRI, deviations between the actual and natural real rates of interest are shown to be insignificant during most of the 1990s and up to most recently. In EMU, the estimate based on the unadjusted interest rate series (first panel) signals periods of loose monetary policy in 1999 and from late 2001 onwards and a restrictive stance in 2000. However, after adjusting for risk premia (second panel), the Eurosystem's monetary policy can no longer be qualified as either significantly expansionary or restrictive, except for some months of tightness in the year 2000.

\section{Graph 7}

Filtered and smoothed real interest rate gaps, unadjusted and risk-adjusted data

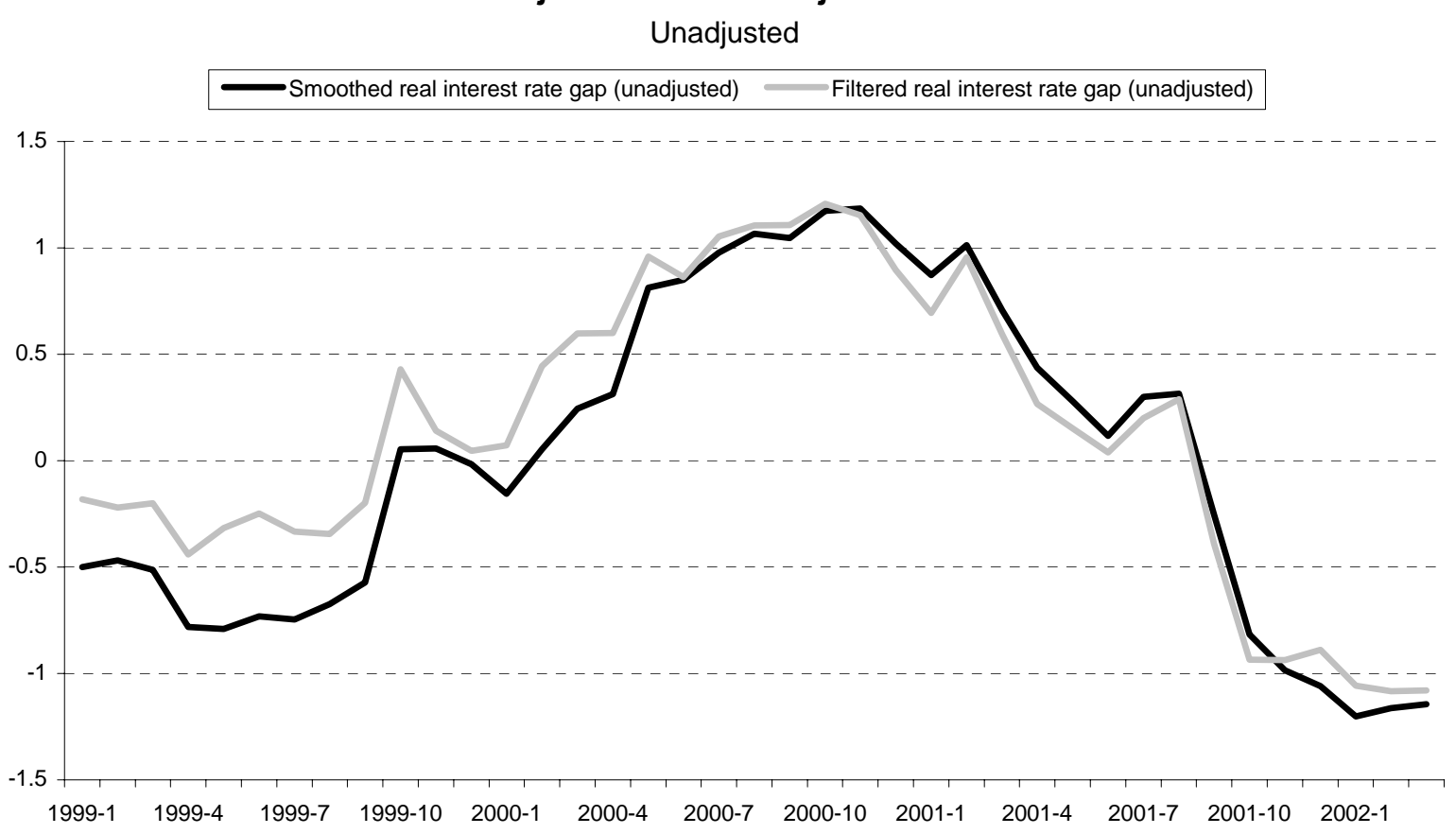




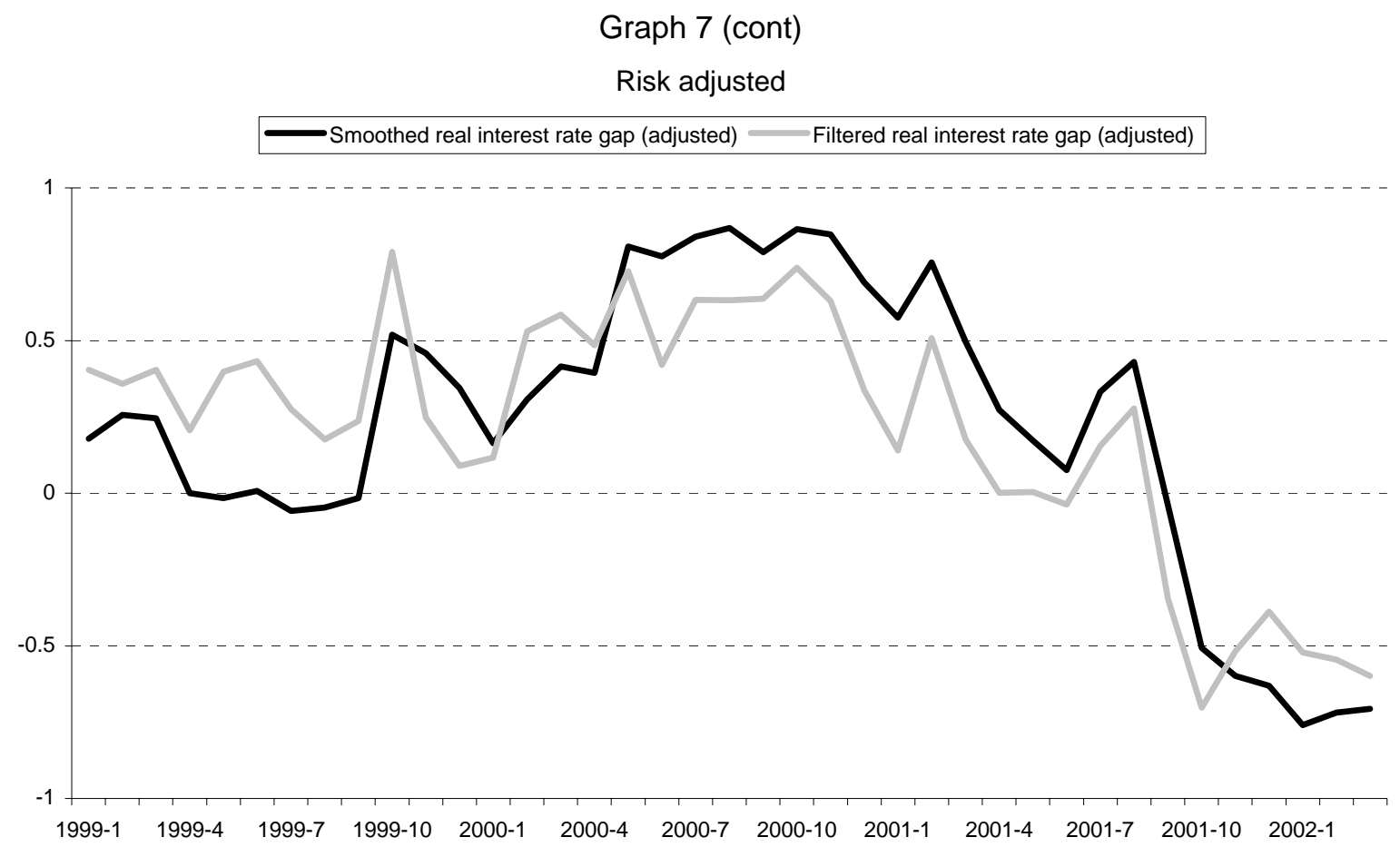

In the final panel of Graph 8 we compare the risk-adjusted natural rate (ie the neutral rate that could have been the guidepost for monetary policy in the absence of risk premia) with the unadjusted real interest rate (ie the real interest rate as it actually prevailed). As expected from Section 3, we find that - seen from this perspective - the aggregate synthetic euro area monetary policy was almost without interruption restrictive (ie the actual rate lay above the $75 \%$ confidence band of the natural-rate estimate) between July 1992 and mid-1998.

Graph 8

The real interest rate, TVNRIs and confidence bands (cb)

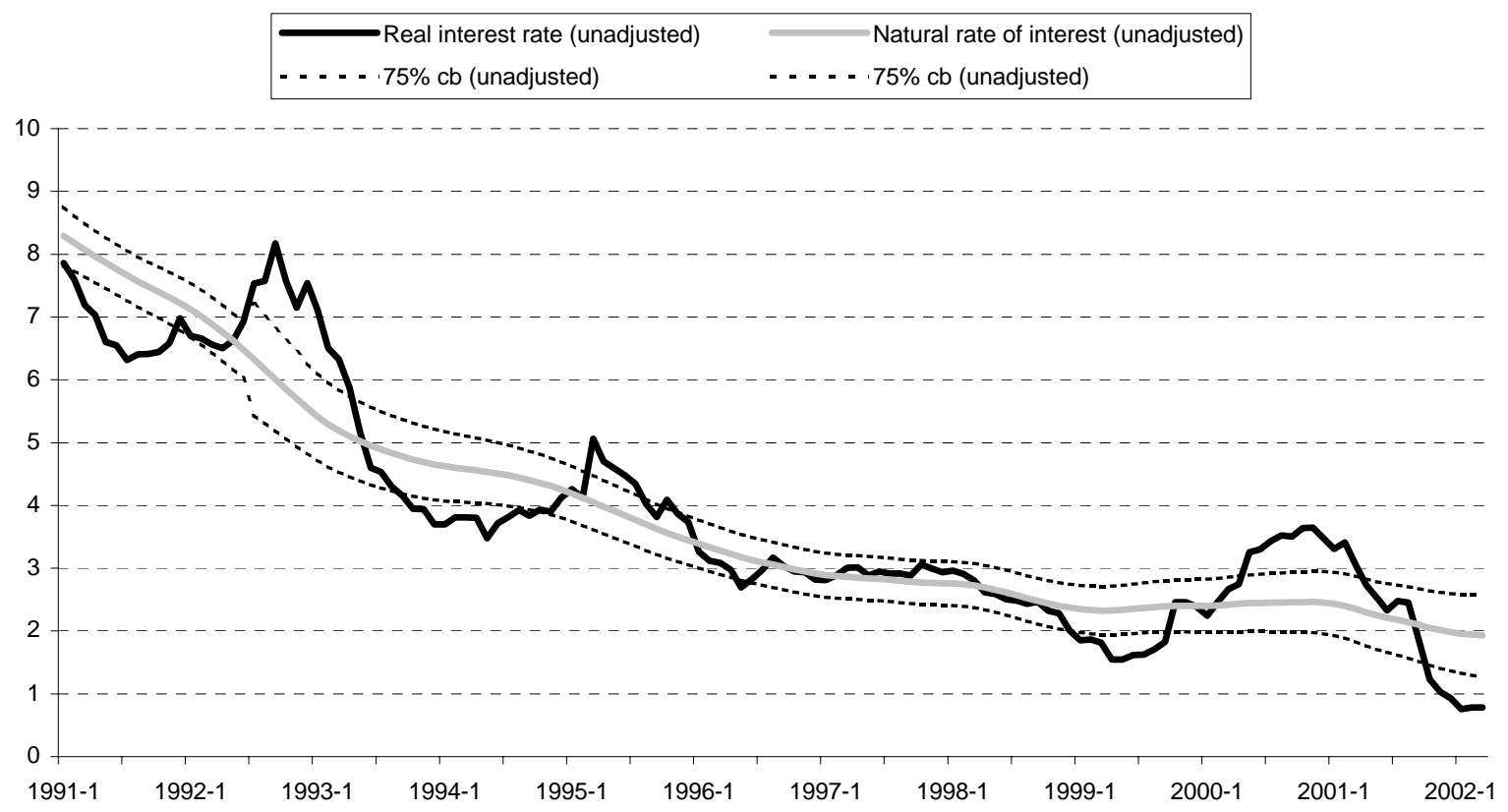


Graph 8 (cont)

\begin{tabular}{|cc|}
\hline Real interest rate (adjusted) & Natural rate of interest (adjusted) \\
\hline & $\ldots$. \\
\hline
\end{tabular}

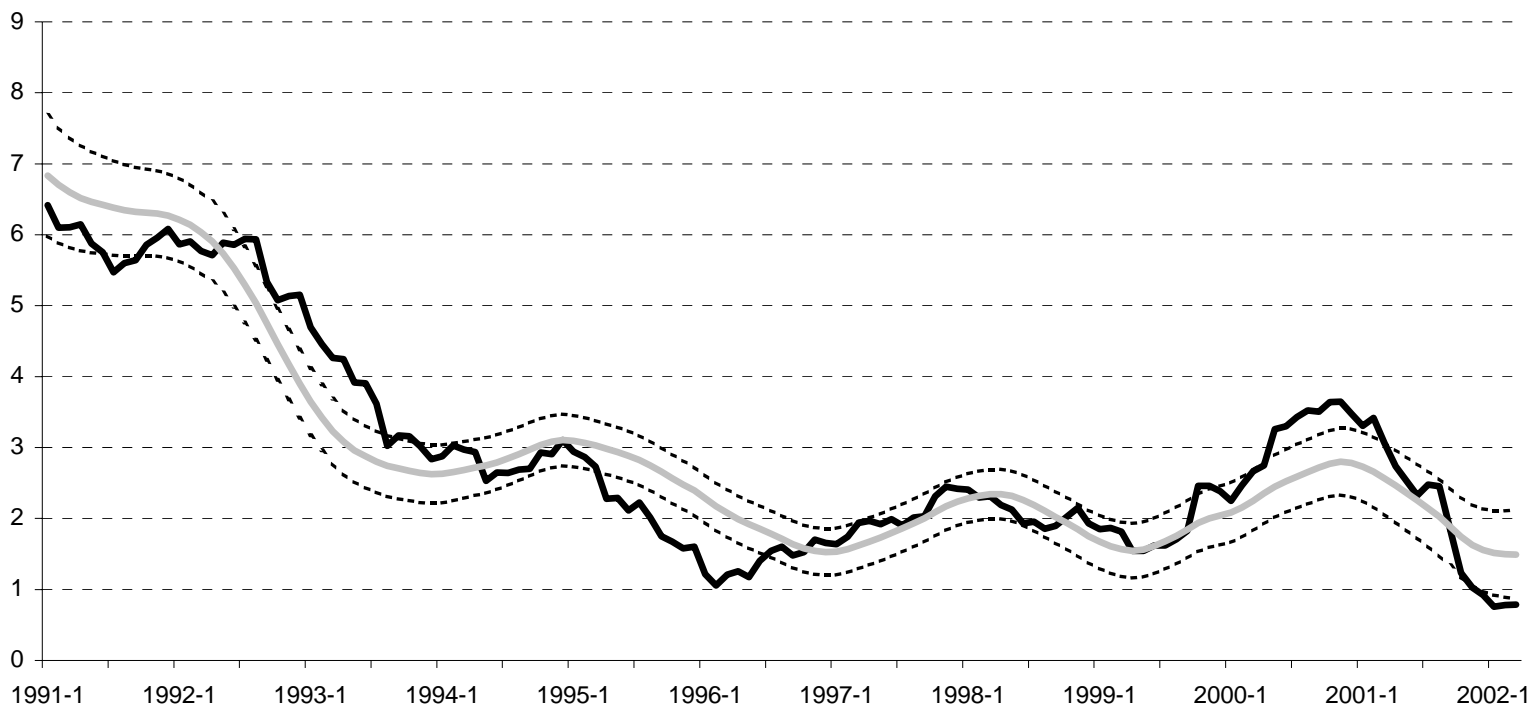

\begin{tabular}{|cc|}
\hline Real interest rate (unadjusted) & Natural rate of interest (adjusted) \\
$\ldots \ldots$. & $\ldots$ \\
\hline
\end{tabular}

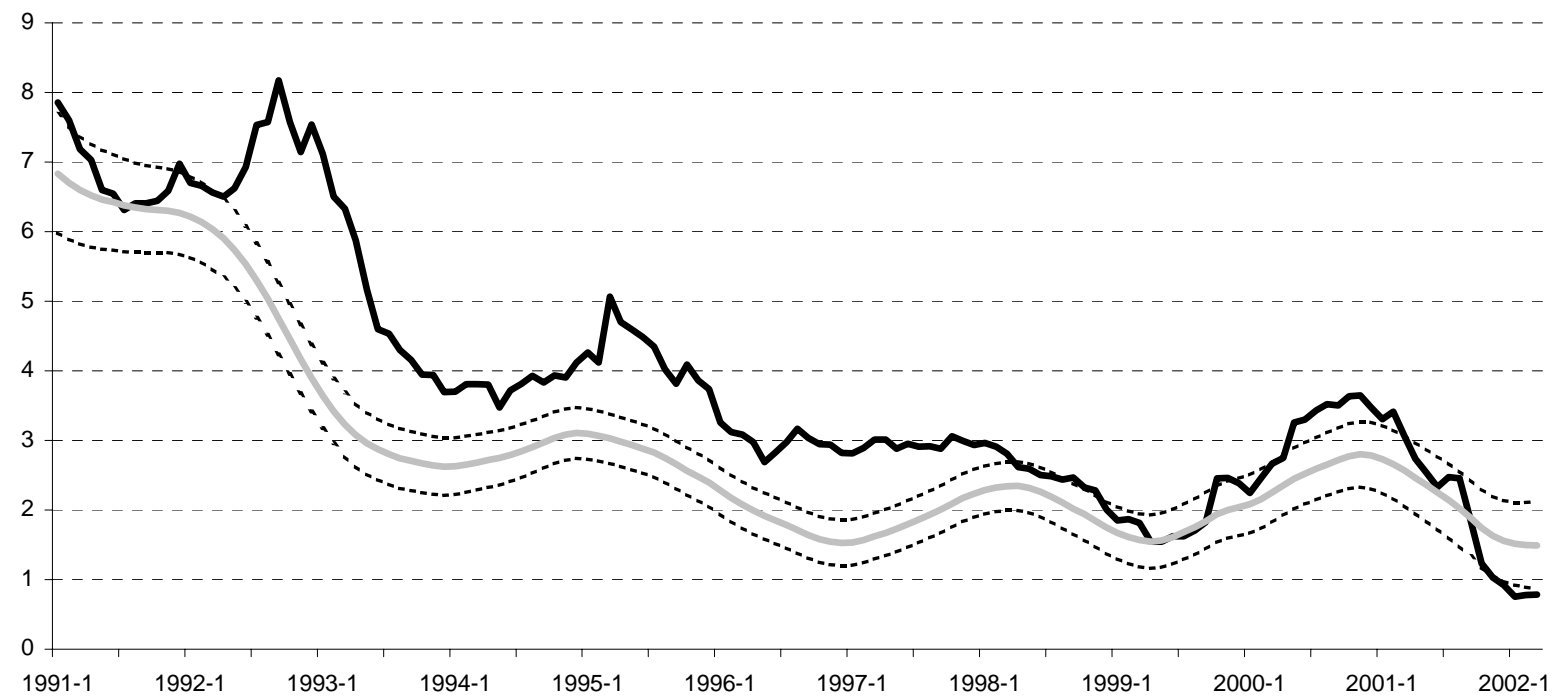

\section{Leading indicator properties of the real interest rate gaps for inflation}

The real interest rate gap is a widely used measure of the monetary policy stance. However, the analysis carried out so far illustrates clearly that the point estimates of the real interest rate gap may differ substantially depending upon the statistical technique used in identifying the natural rate of interest. Significant differences about the stance of monetary policy arise as well if the euro area interest rate series is adjusted for interest rate premia in the pre-EMU period. On this last point, we are interested in the advantages or disadvantages of using the adjusted series for monetary policy evaluation. This section compares the adjusted and unadjusted series in terms of the properties of the real interest rate gap emerging from both datasets as a leading indicator of inflation in the euro area. 


\section{Graph 9}

\section{Leading indicator properties: real interest rate gaps}

Correlation between monthly inflation and the real interest rate gap at lag $k$

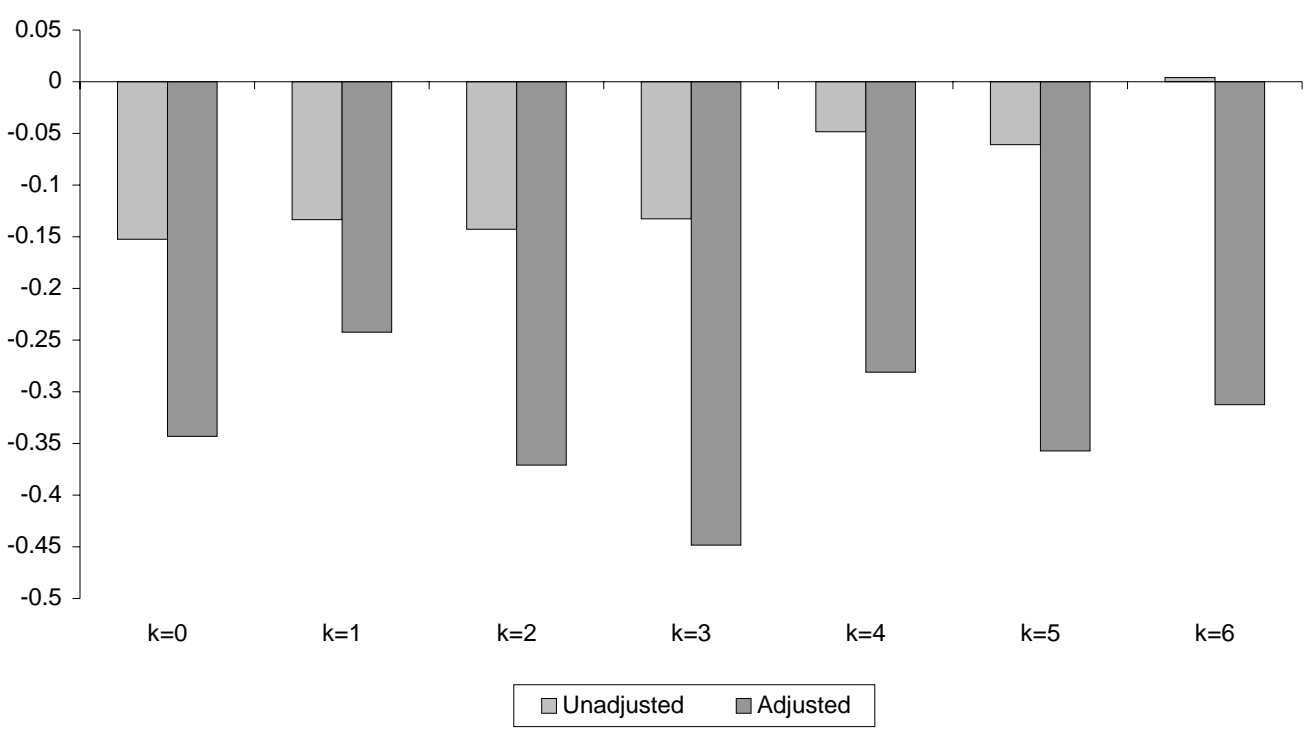

Correlation between annual inflation and the real interest rate gap at lag $k$

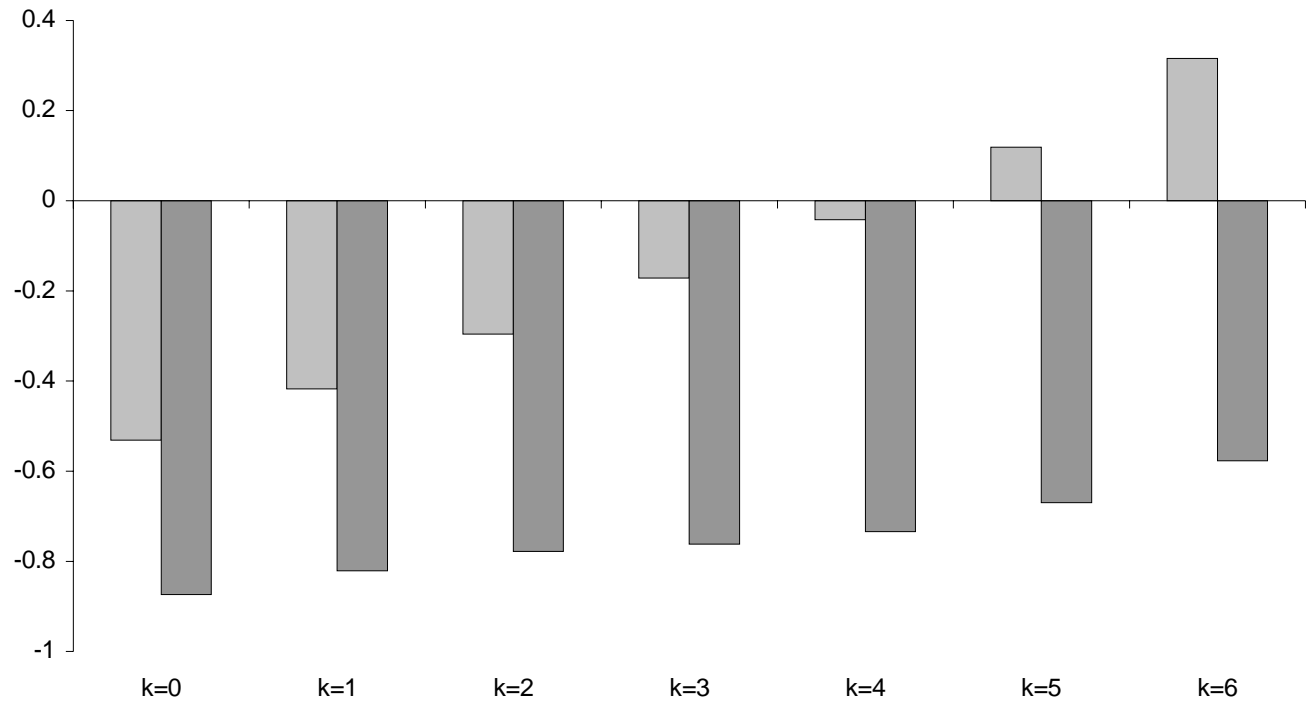

Graph 9 shows the correlation between monthly (upper panel) and annual (lower panel) inflation and the real-time (ie filtered) estimates of the ex ante real interest gap ${ }^{16}$ at different lags, $k$, ranging from zero to six months. The correlations refer to the period between January 1999 and March $2002 .{ }^{17}$ The correlation up to a lag of six months appears always negative for the risk-adjusted real interest rate

16 The filtered estimates of the real interest rate gap were computed using the multivariate unobserved components approach for both series.

17 The complete sample of national interest rates up to December 1998 is required to perform the adjustment, so real-time estimates based on adjusted data prior to 1999 would be misleading as they would not be representative of the information that is available to the monetary policy authority at a given point in time. 
gap series, while the correlation between the real interest rate gap emerging from the unadjusted series and inflation turns positive for lags of more than five (monthly inflation rate) or four (annual inflation rate) months. The correlation is higher in absolute terms for the adjusted series at all evaluated lags, giving a clear indication of the superior leading-indicator properties of the adjusted real interest rate gap. The negative correlation between the (adjusted) real interest rate gap and inflation is consistent with economic theory (see, for example, Neiss and Nelson (2001)). This suggests that the real interest rate gap resulting from the adjusted interest rate series may serve better as an indicator of the monetary policy stance than the one calculated from the original series of aggregated EMU shortterm interest rates.

\section{Risk premium adjustment and euro area feedback rule estimates}

In this section we assume that monetary policy in the euro area can be represented by an interest rate feedback rule à la Clarida et al (1998), such that the central bank sets the short-term interest rate $\left(\tilde{i}_{t}\right)$ according to the following rule $e^{18}$

$\tilde{i}_{t}=i_{t}^{*}+\delta\left[E\left(\pi_{t+12}-\pi_{t+12}^{*} \mid \Omega_{t}\right)\right]+\gamma\left[E\left(g_{t} \mid \Omega_{t}\right)\right]$

where $i_{t}^{*}$ is the time-varying nominal interest rate target. Monetary policy reacts to changes in the deviation of expected inflation from some bliss value $\left(\pi_{t}^{*}\right)$ and to changes in the expected output gap, $g_{t}$. We further assume interest rate smoothing, so that the actual interest rate is given by

$i_{t}=(1-\eta) \tilde{i}_{t}+\eta i_{t-1}+\zeta_{t}$

where $\eta \in[0,1]$ is the smoothing parameter and $\zeta_{t}$ is an iid error. Combining equations (9) and (10), we can write

$i_{t}=(1-\eta) r_{t}^{*}+(1-\eta) \delta\left(\pi_{t+12}-\pi_{t+12}^{*}\right)+(1-\eta) \gamma g_{t}+(1-\eta) \pi_{t+12}+\varphi_{t}$

where $r_{t}^{*}$ is the natural, time-varying, real interest rate (defined as the natural nominal interest rate minus expected inflation), and the error term, $\varphi_{t}$, is a linear combination of the error in equation (10) and the forecast errors in predicting the inflation rate, its "normal rate", $\pi_{t}^{*}$, and the output gap. The estimation of equation (11) was carried out using the general method of moments, as suggested in Clarida et al (1998). The instruments used were past values of inflation, the interest rate and the output gap. The output gap is taken to be the smoothed estimate of the cyclical components of output and inflation in the multivariate unobserved components model for the risk-unadjusted interest rate data. The natural rate of interest data correspond to the smoothed estimates of the TVNRI, and the inflation target is taken to be the smoothed estimate of the trend in inflation extracted from the multivariate unobserved components model with the original interest rate data.

Table 1 reports the estimates of the structural parameters in equation (11) using risk-unadjusted and adjusted data (and thus unadjusted and adjusted TVNRIs). The estimated parameters corresponding to reactions of monetary policy to inflation and the output gap are higher for risk-unadjusted interest rate data than for adjusted data, although there is no statistically significant difference for the reaction to inflation deviations from trend. Notice that there is a basic difference in the interpretation of the parameter associated with the reaction to inflation in our specification compared to that of Clarida et al (1998). In the case of targeting a fixed level of inflation (as in Clarida et al (1998)), disinflationary monetary policy corresponds to an estimate of $\delta$ significantly greater than one. In contrast, when the targeted level of inflation is assumed variable, as in our case, a $\delta$ parameter not significantly different

18 For the pre-EMU period, this amounts to the assumption that the (weighted) average of euro area central banks' monetary policies can be represented by means of an aggregate reaction function. 
from one (as is the case in the setting with adjusted interest rate data) is still consistent with disinflation, given the decreasing trend of inflation.

Table 1

Estimated monetary policy reaction functions

(euro area, 1991:01-2002:03)

\begin{tabular}{|c|c|c|}
\hline Parameter & Risk-unadjusted interest rate data & Risk-adjusted interest rate data \\
\hline$\eta$ & $0.825^{\star \star *}(0.009)$ & $0.831^{\star \star \star}(0.013)$ \\
\hline$\delta$ & $1.515^{\star * \star}(0.272)$ & $1.232^{* * *}(0.374)$ \\
\hline$\gamma$ & $0.979^{\star * *}(0.374)$ & $0.386^{* * *}(0.118)$ \\
\hline Sargan test & $16.921(p$-value $=0.963)$ & $16.399(p$-value $=0.971)$ \\
\hline
\end{tabular}

$\left.{ }^{*}\left({ }^{* *}\right){ }^{\star \star \star *}\right]$ stands for significance at the $10 \%(5 \%)$ [1\%] level. Estimation carried out by GMM, using past values of interest rates, inflation and the output gap as instruments.

Substantial differences, however, appear in the estimate of the reaction of aggregate monetary policy in EMU to the output gap. For unadjusted data the results imply that monetary policy reacted in a oneto-one fashion to the output gap, an estimate more than twice greater than the one corresponding to the adjusted interest rate data. The source of these contradictory results appears to lie in the risk premium component of the aggregate interest rate data in the pre-EMU period. The time variation of the interest rate risk premium happens to coincide closely with the cyclical variation in the output gap. ${ }^{19}$ Thus, if a reaction function as above is estimated for pre-EMU aggregate euro area monetary policy using non-risk-adjusted nominal interest rates, the dynamics of policy interest rates which are actually driven by risk premia are erroneously taken to be reactions of monetary policy to the output gap. This is confirmed by our finding that the correlations between the national interest rate risk premia and the corresponding output gaps are negative or not significantly different from zero in all individual euro area countries, with the exception of Finland. ${ }^{20}$ The high response coefficient of monetary policy to the output gap when using risk-unadjusted data seems to be thus a statistical artefact. The coefficients estimated on the basis of risk-adjusted interest rate data are more in line with the estimates reported by, for example, Clarida et al (1998).

\section{Summary and conclusions}

This paper has pursued five objectives: first, to estimate time-varying natural rates of interest for the euro area, using a structural statistical model; second, to explore the consequences of pre-EMU national interest rate risk premia for TVNRI estimates; third, to evaluate the robustness of such estimates in real-time settings and when bearing in mind the wide confidence bands of such estimates; fourth, to explore the leading indicator properties of our real interest rate gap estimates for euro area inflation; and fifth, to estimate feedback rules for monetary policy in EMU, focusing on the differences implied by the use of raw aggregate interest rate data for the pre-EMU period.

We estimate the TVNRI by means of a multivariate unobserved components approach, with aggregate monthly euro area data (January 1991 to March 2002) on ex ante real interest rates, core inflation and

19 The correlation between the aggregate risk premium and the output gap is 0.685 .

20

The correlations range between -0.66 for the Netherlands and 0.35 for Finland. The lack of synchronisation across national business cycles explains, thus, the coincidence of expansions and risk premium in the pre-EMU aggregate series and therefore the relatively higher response of monetary policy to the output gap implied by the estimation of feedback rules for the euro area using raw aggregated interest rate data. 
industrial production; the (unobserved) trend component in the real interest rate for the euro area is taken to be the natural rate of interest. Our first estimate is based on simple aggregated money market rates for the pre-EMU part of our sample and yields a TVNRI that falls from $8 \%$ in early 1991 to around $2 \%$ by the start of EMU and has remained there ever since. This contrasts sharply with a fixed estimate based on the sample average of $3.8 \%$.

However, simple aggregate money market interest rate data were, in particular until the mid-1990s, distorted by various risk premia no longer relevant in the new regime of the euro area. We extract those risk premia from national interest rate data and derive a synthetic measure of the aggregate euro area money market interest rate. The risk premium is hypothesised to be the part of each country's (nominal) interest rate spread with Germany unexplained by differentials in inflation expectations and output gap desynchronisation. The estimated risk premium is found to have coincided closely with the bouts of ERM tensions in the early and mid-1990s and converges towards zero by end-1998. On the basis of the regime change adjusted interest rate series, we re-estimate the TVNRI: it now fluctuated between 1 and 31/2\% between 1994 and spring 2002. The average over the full-sample period is close to $3 \%$.

The real interest rate gaps derived from the unadjusted and adjusted TVNRIs differ substantially in terms of the derived real interest rate gaps, thus yielding different ex post assessments of European monetary policies pre-EMU and in EMU. In several instances (1993-94, 1995-96, 1999), the riskadjusted and the unadjusted real-rate gap would have yielded opposite monetary policy advice. Contrary to the unadjusted estimate, euro area monetary policy is no longer qualified as expansionary in 1999 and is also considered less expansionary in 2002. On the other hand, the adjusted real interest gap suggests a lesser degree of restrictiveness during the upswing in 2000-01. More generally, the adjusted estimates suggest smoother and more cautious changes in the Eurosystem's policy stance.

For practical monetary policy estimates we also explore to what extent "real-time" estimates deviate from full-sample estimates. We find that the real-time estimation error reaches up to $1 / 2$ percentage point for both the risk premia unadjusted and adjusted series. This confirms the finding in the literature that policy rules based on unobserved macroeconomic variables, such as the natural rates of output, unemployment or interest rate - or the derived "gaps" - involve a substantial margin of error if applied "real-time" and should thus be used cautiously. The rather wide $75 \%$ confidence bands around our TVNRI estimates further add to practical difficulties in applying TVNRI-based monetary stance indicators or feedback rules.

We conclude the paper with two policy applications. First, we find the risk-adjusted real interest gap to perform considerably better as a leading indicator for euro area inflation than the non-adjusted series. Second, using our TVNRI estimates, we estimate monetary policy feedback rules for the euro area, in order to assess ex post the relative weights attached to inflation and output stabilisation by the ECB Governing Council and by its predecessor pre-EMU euro area central banks. We show that, for the pre-EMU period, using risk-unadjusted policy rates leads to periods of high risk premia being erroneously taken as monetary policy replies to the output gap; by contrast, using risk-adjusted policy rates yields an estimate of the reaction of monetary policy to the output gap corresponding approximately to an increase of 40 basis points for a $1 \%$ positive deviation of output from potential output. A positive deviation of inflation from its trend of $1 \%$ is estimated to have triggered approximately a $1.2 \%$ increase in short-term interest rates. 


\section{Appendix: \\ Estimation results for the multivariate unobserved components models}

(A) Results using original interest rate data

\begin{tabular}{c|c}
\hline Hyperparameter & Estimate \\
\hline$\rho$ & 0.969 \\
$\Sigma_{u}$ & 0.178 \\
$\Sigma_{\psi}$ & {$\left[\begin{array}{ccc}0.005 & \\
-0.001 & 0.0005 & \\
-7.27 \times 10^{-5} & -7.64 \times 10^{-5} & 3.23 \times 10^{-5}\end{array}\right]$} \\
& {$\left[\begin{array}{ccc}0.0002 & & \\
-0.0003 & 0.0004 & \\
1.94 \times 10^{-5} & -2.69 \times 10^{-5} & 1.90 \times 10^{-6}\end{array}\right]$} \\
$\Sigma_{\omega}$ & {$\left[\begin{array}{ccc}0.032 & & \\
-0.004 & 0.005 & \\
0.0002 & 5.44 \times 10^{-5} & 1.97 \times 10^{-6}\end{array}\right]$} \\
\hline
\end{tabular}

Residual analysis:

\begin{tabular}{l|c|c|c}
\hline & Real interest rate & Inflation & Industrial production \\
\hline Standard error & 0.218 & 0.094 & 0.008 \\
Jarque-Bera test statistic & 26.85 & 2.306 & 1.655 \\
Durbin-Watson statistic & 2.019 & 1.892 & 1.926 \\
\hline
\end{tabular}

(B) Results using adjusted interest rate data

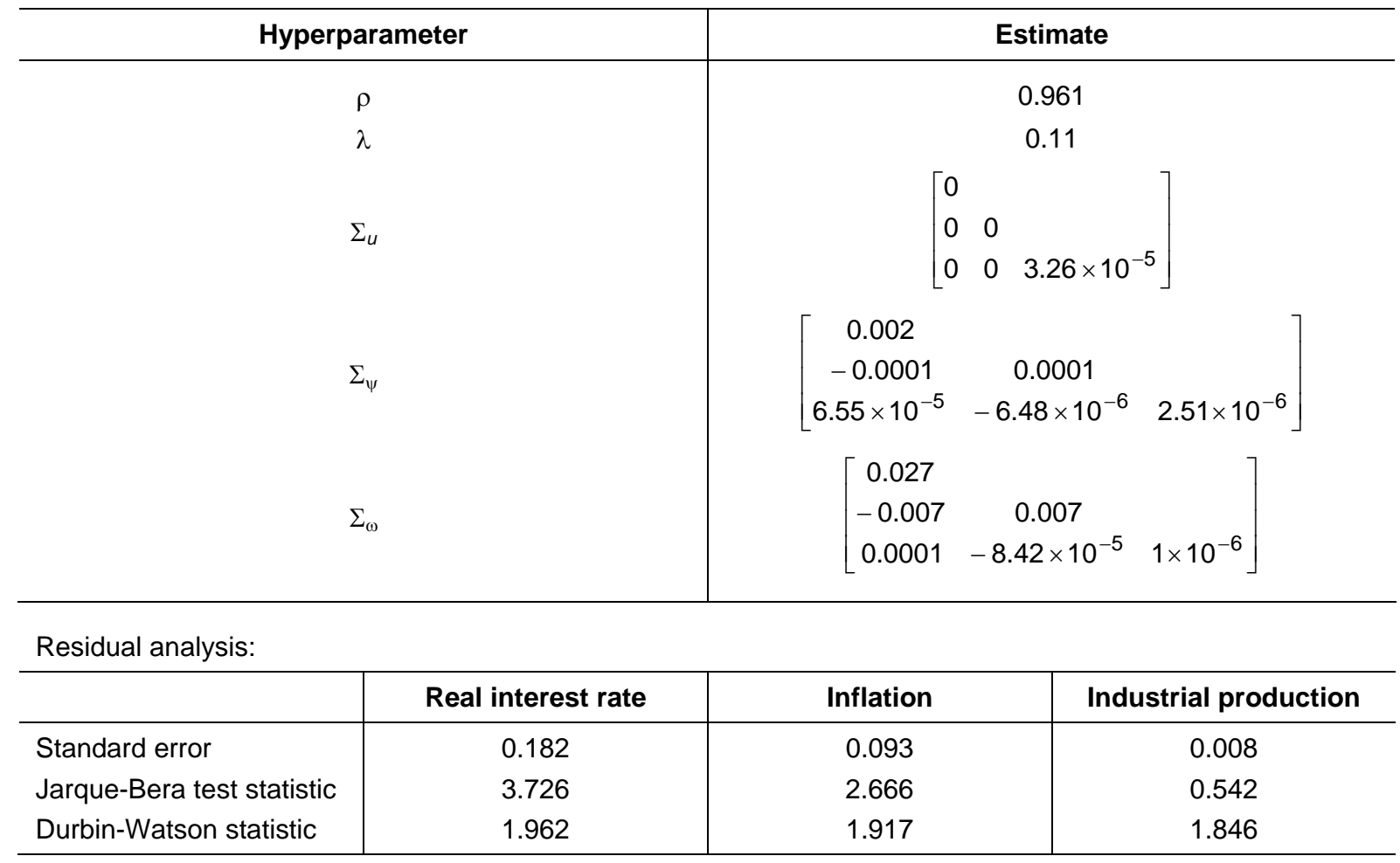




\section{References}

Bomfim, A (1997): "The equilibrium fed funds rate and the indicator properties of term-structure spreads", Economic Inquiry, October, vol 35, no 4, pp 830-46.

Christiansen, $\mathrm{H}$ and C Pigott (1997): "Long-term interest rates in globalised markets", OECD Working Papers, no 175.

Clarida, R, J Galí and M Gertler (1998): "Monetary policy rules in practice - some international evidence", European Economic Review, vol 42, pp 1033-67.

Cogley, T and J M Nason (1995): "Effects of the Hodrick-Prescott filter on trend and difference stationary time series: implications for business cycle research", Journal of Economic Dynamics and Control, vol 19, pp 253-78.

Harvey, A C (1989): Forecasting, structural time series and the Kalman filter, Cambridge University Press, Cambridge.

Harvey, A C and A Jaeger (1993): "Detrending, stylized facts and the business cycle", Journal of Applied Econometrics, vol 8, pp 231-47.

Hodrick, R J and E C Prescott (1997): "Postwar US business cycles: an empirical investigation", Journal of Money, Credit and Banking, vol 29, pp 1-16.

Jenkinson, N (1996): "Saving, investment, and real interest rates", Bank of England Quarterly Bulletin, February.

Laubach, T and J C Williams (2001): Measuring the natural rate of interest, Board of Governors of the Federal Reserve System, November.

Neiss, K S and E Nelson (2001): "The real interest rate gap as an inflation indicator", Bank of England Working Paper, no 148, December.

Orphanides, A (2001): "Monetary policy rules based on real-time data", American Economic Review, September.

Orphanides, A and J C Williams (2002): "Robust monetary policy rules with unknown natural rates", Brookings Papers on Economic Activity, forthcoming.

Orr, A, M Edey and M Kennedy (1995): "Real long-term interest rates: the evidence from pooled-timeseries", OECD Economic Studies, no 25.

Smets, F and R Wouters (2002): "An estimated stochastic dynamic general equilibrium model of the euro area”, ECB Working Paper, no 171, August.

Taylor, J (1993): "Discretion versus policy rules in practice", Carnegie-Rochester Conference Series on Public Policy, vol 39, pp 195-214.

Wicksell, K (1936): Interest and prices, Macmillan, London (translation of the 1898 edition by R F Kahn).

Woodford, M (2002): "A neo-Wicksellian framework", in Interest and prices: foundations of a theory of monetary policy, Chapter 4, mimeo, http://www.princeton.edu/ woodford/. 